\title{
Predicting riverine dissolved silica fluxes to coastal zones from a hyperactive region and analysis of their first-order controls
}

\author{
Jens Hartmann · Nils Jansen · Hans H. Dürr • \\ Akira Harashima $\cdot$ Kenji Okubo $\cdot$ Stephan Kempe
}

Received: 15 October 2007 / Accepted: 26 October 2008/Published online: 20 January 2009

(C) Springer-Verlag 2009

\begin{abstract}
Silicate weathering and resulting transport of dissolved matter influence the global carbon cycle in two ways. First by the uptake of atmospheric/soil $\mathrm{CO}_{2}$ and second by providing the oceanic ecosystems via the fluvial systems with the nutrient dissolved silica (DSi). Previous work suggests that regions dominated by volcanics are hyperactive or even "hot spots" concerning DSi-mobilization. Here, we present a new approach for predicting DSi-fluxes to coastal zones, emphasizing "first-order" controlling factors (lithology, runoff, relief, land cover and temperature). This approach is applied to the Japanese Archipelago, a region characterized by a high percentage of volcanics $(29.1 \%$ of surface area). The presented DSi-flux model is based on data of 516 catchments, covering approximately $56.7 \%$ of the area of the Japanese Archipelago. The spatial distribution of
\end{abstract}

Electronic supplementary material The online version of this article (doi:10.1007/s00531-008-0381-5) contains supplementary material, which is available to authorized users.

J. Hartmann $(\bowtie) \cdot$ N. Jansen · S. Kempe

Institute of Applied Geosciences, Darmstadt University

of Technology, Schnittspahnstrasse 9,

64287 Darmstadt, Germany

e-mail: geo@hattes.de

H. H. Dürr

Faculty of Geosciences, Utrecht University, Heidelberglaan 2, 3508 TC Utrecht, The Netherlands

\author{
A. Harashima \\ Water and Soil Environment Division, National Institute \\ for Environmental Studies, 16-2 Onogawa, \\ Tsukuba, Ibaraki 305-8506, Japan

\section{K. Okubo} \\ Division of Social Engineering and Environmental Management, \\ Graduate School of Environmental Science, Okayama \\ University, 3-1-1, Tsushima-Naka, Okayama 700-8530, Japan
}

lithology—one of the most important first order controlsis taken from a new high resolution map of Japan. Results show that the Japanese Archipelago is a hyperactive region with a DSi-yield 6.6 times higher than the world average of $3.3 \mathrm{t} \mathrm{SiO}_{2} \mathrm{~km}^{-2} \mathrm{a}^{-1}$, but with large regional variations. Approximately $10 \%$ of its area exceeds 10 times the world average DSi-yield. Slope constitutes another important controlling factor on DSi-fluxes besides lithology and runoff, and can exceed the influence of runoff on DSi-yields. Even though the monitored area on the Japanese Archipelago stretches from about $31^{\circ}$ to $46^{\circ} \mathrm{N}$, temperature is not identified as a significant first-order model variable. This may be due to the fact that slope, runoff and lithology are correlated with temperature due to regional settings of the Archipelago, and temperature information is substituted to a certain extent by these factors. Land cover data also do not improve the prediction model. This may partly be attributed to misinterpreted land cover information from satellite images. Implications of results for Earth System and global carbon cycle modeling are discussed.

Keywords Japan · Dissolved silica - Empirical model · Chemical weathering

\section{Introduction}

Silicate weathering is an important process within the global carbon cycle because soil and thus atmospheric $\mathrm{CO}_{2}$ is 'consumed' by silicate weathering. On time scales of thousands to millions of years this process is capable to reduce atmospheric $\mathrm{CO}_{2}$ concentration significantly (Kempe 1979; Kempe and Degens 1985; Berner and Kothavala 2001; Lenton and Britton 2006). Dissolved silica (DSi) flux to coastal zones is also an important factor 
in the oceanic carbon cycle due to the importance of DSi as a nutrient for diatom growth (e.g., Kristiansen and Hoell 2002; Buesseler et al. 2007; Harashima 2007). Diatom abundance is linked to carbon burial rates in coastal systems and in the open ocean (Buesseler et al. 2007; Harashima 2007). DSi depletion in surface waters due to diatom DSi up-take impedes diatom blooms. Thus surface water DSi concentration constitutes an important factor for coastal waters to act as a C-sink due to carbon burial. The most important sources for marine 'new' DSi are rivers with an estimated proportion of $80 \%$ (Treguer et al. 1995). Because of these implications it is important for global biogeochemical cycles to predict or estimate fluvial DSifluxes regionally and globally.

The terrestrial silicate weathering-derived DSi is transported via rivers to coastal zones. Previous work suggests that only a few 'first-order' factors control these silica fluxes. These include lithology (Bluth and Kump 1994; Hartmann et al. 2007a) and runoff (Bluth and Kump 1994) as the most important factors. Chemical weathering and subsequent DSi-fluxes are also influenced by temperature (Drever and Zobrist 1992), land cover (Gislason et al. 1996; Moulton et al. 2000; Fulweiler and Nixon 2005), mechanical erosion, probably linked to relief or slope (Millot et al. 2002; West et al. 2005; Lyons et al. 2005), as well as lakes and dams because they provide sediment burial sites for diatom opal (amorphous Si = ASi) (Humborg et al. 2002, 2006). The process of ASi deposition within fluvial systems is enhanced by eutrophication providing $\mathrm{P}$ and $\mathrm{N}$ for excessive diatom blooms (Turner et al. 2003).

Hyperactive areas and hot spots of silicate weathering have recently received attention due to their link to the global C cycle (cf. Gaillardet et al. 1999; Dessert et al. 2003). Hyperactive areas are classified as regions exceeding five times and hot spots as areas exceeding ten times world average yields (Meybeck et al. 2006). For semienclosed regional seas (Meybeck et al. 2007) riverine inputs are the most significant source of new DSi as shown for regional seas adjacent to Japan, i.e., the East China Sea, the Sea of Japan and the smaller Seto Inland Sea. DSi river input to these seas is approximately 74, 83 and $97 \%$, respectively (considering river input, atmospheric deposition and marine intrusion as being 100\%), with some uncertainty in the estimate of marine intrusion (Chen et al. 2004; Hartmann et al. 2007b). Because of missing data, ASi was not considered in these budgets.

One strategy to estimate DSi-fluxes to coastal areas are measurements at the river outlets. Unfortunately only few data are available for the large world rivers (Garnier et al. 2006). The largest published global, representative data base lists DSi-fluxes for 215 rivers (Meybeck and Ragu 1995). Global average concentrations of DSi were investigated, e.g., by Garnier et al. (2006) and Meybeck (2005).
Up to now global or regional models predicting river DSi-fluxes are still missing. However, previous models of global and regional riverine fluxes of alkalinity, organic carbon, suspended matter as well as $\mathrm{N}$ and $\mathrm{P}$ showed that it is possible to predict these fluxes based on empirical functions derived from training data sets (Ludwig et al. 1996; Verstraeten and Poesen 2002; Amiotte-Suchet et al. 2003; Bouwman et al. 2005; Seitzinger et al. 2005; Beusen et al. 2005; Verstraeten 2006; Syvitski and Milliman 2007). The regional scale is defined as ranging from $10^{4}$ to $10^{7} \mathrm{~km}^{2}$ as suggested by IPCC (Root et al. 2005). Derived empirical or statistical prediction functions from previous works use geodata representing characteristics such as runoff, lithology and land cover of each watershed and water quality data for model calibration. Some approaches use statistical approaches like multiple linear regression or nonlinear regression to develop lumped models. Models are sometimes enhanced by mechanistical components for spatial explicit application (Seitzinger et al. 2005). Mechanistical components are in general not based on functions identified from analysis of training data.

In addition, entirely process-based models of DSi-fluxes for individual rivers, emphasizing instream biogeochemical processes, were developed (Garnier et al. 2002, 2006; Sferratore et al. 2005). Because a large number of parameters have, however, to be adjusted for each river system, these models are not easily applicable to larger scales. Simple transfer of existing models to other river systems is constrained by differences in climate, internal geomorphical structure (e.g., river bed morphology, etc.), ecosystem structure, anthropogenic influence, as well as the extent of available databases for parameterization. Specifically, the estimates of DSi-fluxes into a river system are based on river budgets.

Global hyperactive regions and hot spots of natural river DSi-fluxes were recently identified by Dürr et al. (2008) based on data from Meybeck and Ragu (1995) applying a budget approach. Accordingly, the world average concentration is around $9.5 \mathrm{mg} \mathrm{SiO}_{2} \mathrm{l}^{-1}$ and the specific $\mathrm{SiO}_{2}$ yield $3.3 \mathrm{t} \mathrm{km}^{-2} \mathrm{a}^{-1}$. The global budget approach by Dürr et al. (2008) is based on cluster effects between relevant first-order controls of DSi-fluxes (lithology, climate, catchment area and runoff). This simplified budget approach indicates that large regions, characterized by flood basalts and volcanic arcs, and specifically humid regions, located in the "Ring of Fire" around the Pacific, are at least hyperactive areas of DSi-fluxes. Pacific catchments contribute $32 \%$ to the global exorheic (draining to the oceans) DSi-fluxes, while they occupy only $17 \%$ of the global exorheic, non-glaciated landmass.

To our knowledge, an empirical DSi-flux model for a regional hyperactive or hot spot multiple river area does not yet exist. One important precondition for such a model 
is the existence of a large data set of river DSi-fluxes. Such a data set exists for Japan based on the extensive work of Kobayashi (1960) from the 1940s to 1970s, covering more than 750 sampling locations (Fig. 1). Here we introduce a new process-based, lumped model approach with application to the Japanese Archipelago applying previous findings about local and regional scale processes and integrating 'first-order' controlling factors on DSi-fluxes.

The present work is organized as follows: available data, their quality and the data analyzing techniques and a preview of data are given. Specifically, for this study a new vector-based lithological map of Japan was developed, incorporating 12 major lithological classes with respect to weathering sensitivity, as developed at the global scale by Dürr et al. (2005). A brief overview of the typical Japanese regional settings is provided, i.e., lithology, river systems, climate and other important factors. In addition, observed DSi-fluxes and model results are reviewed. Influences of proposed first-order controls on DSi-fluxes are discussed. Implications for modeling of the global carbon cycle are discussed.

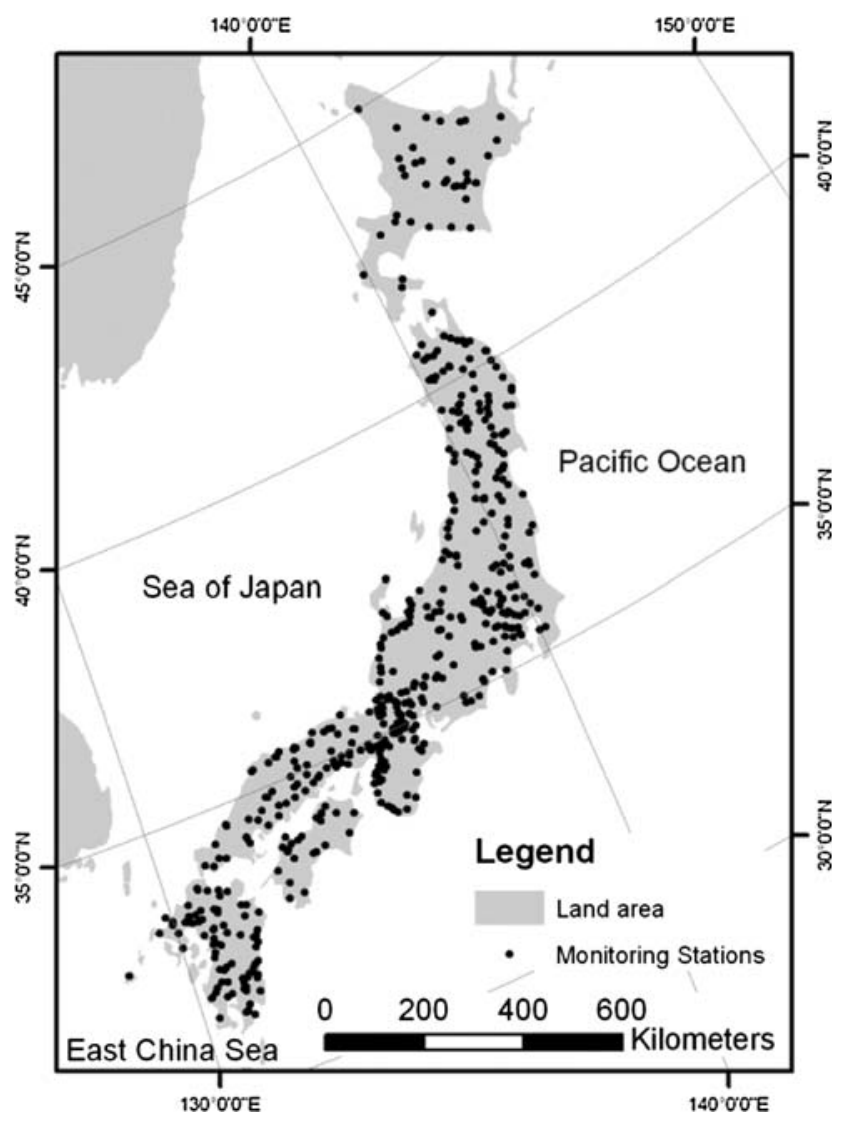

Fig. 1 Main islands of the Japanese Archipelago and sampling locations at river sites used for modeling. Islands in the southwest were cut out for better presentation and no sampling location from this area was used in this study

\section{Data handling and analysis techniques}

Hydrochemical data and geodata handling

Documents containing the summary of the work of Kobayashi (1960) were untouched and forgotten for nearly two decades in a warehouse at Okayama University, Japan (cf. Harashima et al. 2006). They contain hydrochemical data of Japanese rivers for 754 sampling locations from basically two sampling periods: 1940/50s and 1970s. In general, 6-12 samples per year and sampling location were taken to represent DSi seasonality. Anthropogenic contamination was avoided, if possible, by using sampling sites upstream of urbanized regions. These data were digitized from the hand-written tables.

The 1970s data were omitted if those of the 1940/50s were available in the immediate vicinity. Sampling locations were discarded if the following quality criteria were not met: (1) every sample of the location shows a chloride concentration $\leq 30 \mathrm{mg}^{-1}$ (to rule out seawater intrusion, anthropogenic contamination and hydrothermal activity); (2) the sample location lies at one distinct river as defined by the river system model derived from the SRTM digital elevation model (see below). In total, 238 sampling locations were omitted for not fully satisfying these criteria. The remaining 516 locations (each defining a catchment) were used for the analysis here and are located in 240 different river basins draining to the Sea of Japan, Seto Inland Sea, the East China Sea or to the Pacific Ocean (Fig. 1).

SRTM digital elevation model (DEM) data from the International Center of Tropical Agriculture (CIAT) (2004) were used to calculate the catchment areas represented by the sampling locations, elevations, slope and flow direction on a grid resolution of $100 \times 100 \mathrm{~m}$, using the GIS software ArcGIS 9.2 (ESRI). The sum of all catchment areas covers about $56.7 \%$ of the considered area of the Japanese Archipelago $\left(213,467 \mathrm{~km}^{2}\right)$. Average slope of catchments are provided in Fig. 2a.

Runoff data with a spatial resolution of $0.5^{\circ}$ from UNH/ GRDC Composite Runoff fields V1.0 (Fekete et al. 2002) were applied to calculate annual runoff from each catchment (Fig. 2b). The total specific DSi-flux for each catchment was obtained by multiplying annual runoff with the annual average DSi concentration (Fig. 3a). Applied runoff data were successfully compared for plausibility with runoff data of approximately 150 catchments provided in Kobayashi (1960).

The digital vector-based geological map of Japan (Geological Survey of Japan 2003) was used to develop a new lithological map of Japan (Fig. 4), applying lithological classes introduced by Dürr et al. (2005). These classes incorporate information on average mineral proportions 
Fig. 2 Average slope and runoff of Japanese river basins are provided in $\mathbf{a}$ and $\mathbf{b}$. Land cover forest distribution is the dominating land cover class on the Japanese Archipelago (c). Second dominant ones are agricultural areas; urban land cover is surprisingly only minor according to applied land cover data (Table 1). Elevation corrected temperature distribution on the Japanese Archipelago reflects regional landscape elevation (d). Figures are from Hartmann (2008)
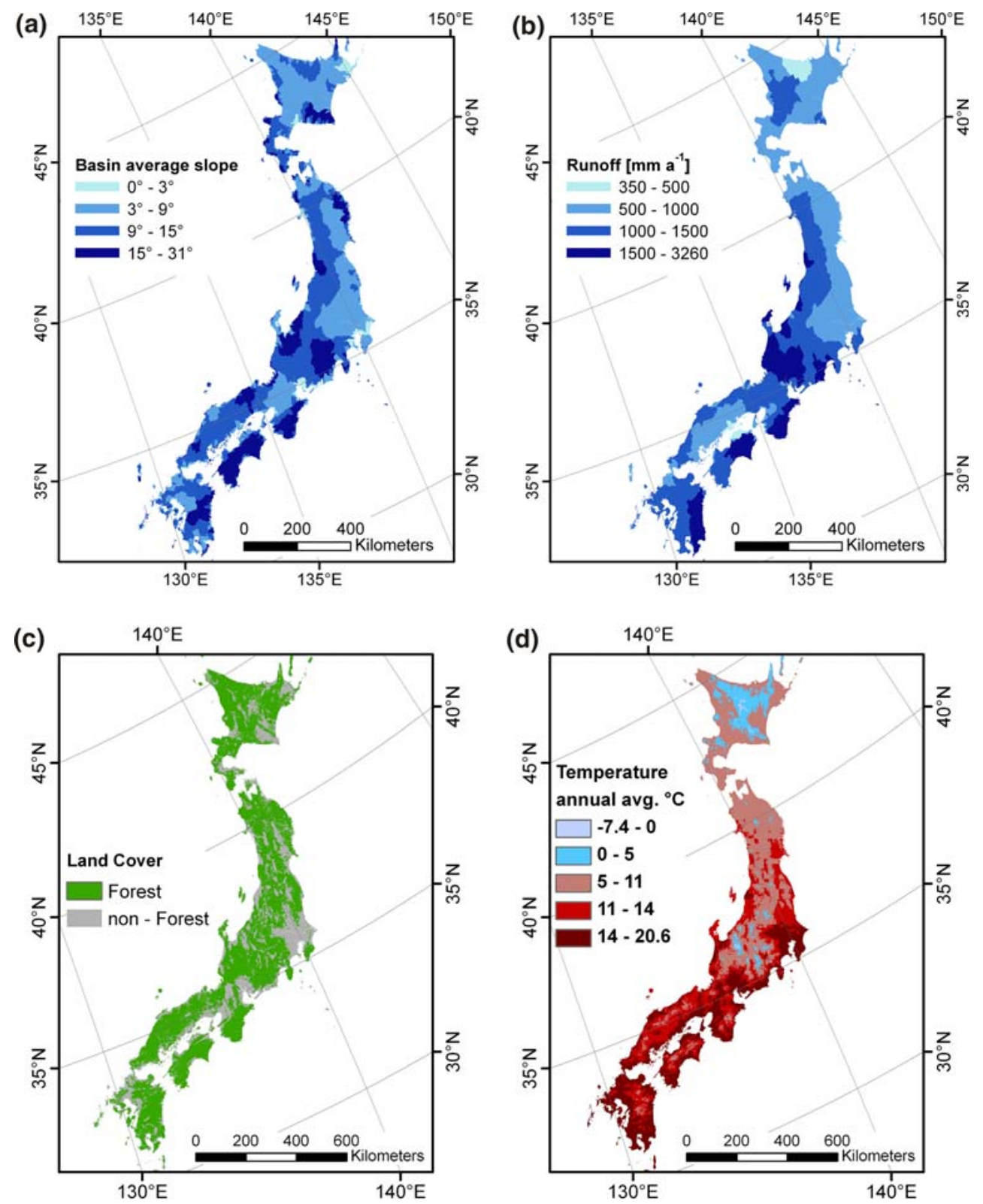

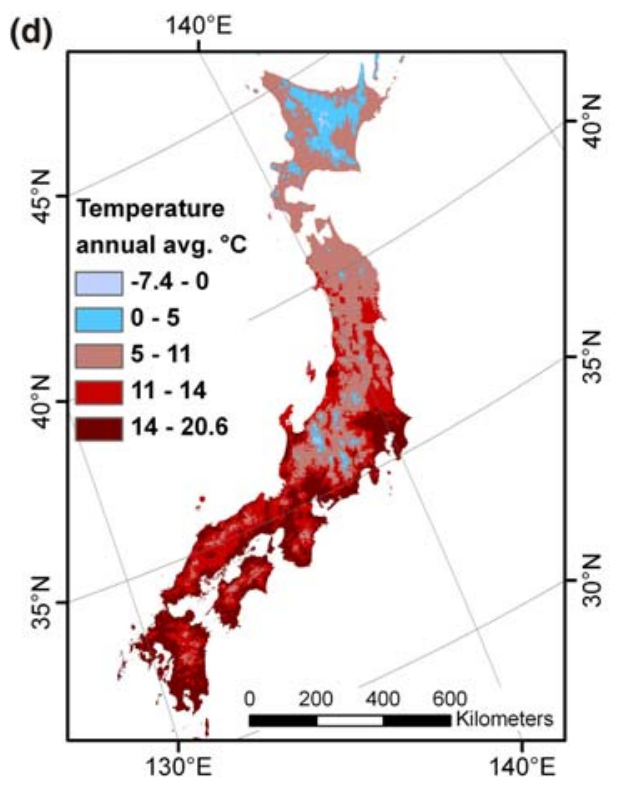

and further lithological properties important to study weathering processes. Pyroclastic Flows (PY) was introduced as an additional lithological class. It includes unconsolidated, young volcanogenic sediments with a considerable porosity and high relevance for silicate weathering (compare Okuda et al. 1995). The number of classes was eventually reduced to 12 (Table 1) because the others were not of relevance to the geological setting of Japan (Takai et al. 1963). Relative proportions of each lithological class were calculated for each catchment using ArcGIS 9.2.

Sizes of land cover classes were calculated for each catchment based on the Land Cover Data for Central Asia
(Tateishi et al. 2003) with resolution of $200 \times 200 \mathrm{~m}$ (Fig. 2c, Table 1). Even though the land cover data are representative of the year 2000 , it is assumed that there are only small differences compared to the time of water sampling. Urbanized areas of Japan comprise only a small proportion of the total area, and land use class proportions, specifically for forests and crop/rice did not change much. An exception could be regions dominated by unconsolidated sediments, where most human activity is concentrated. A cross-check with older maps was conducted but not many differences for most regions were detected.

Temperature data (resolution $10^{\prime}$ ) from the International Water Management Institute (2000) were applied to 
Fig. 3 Calculated DSi-fluxes of catchments defined by the sampling locations after Kobayashi are given in a. Modeled DSi-fluxes are shown in b. Only 37 catchments of the modeled DSi-fluxes (b) are characterized by specific DSifluxes lower than world average. They cover only $162.9 \mathrm{~km}^{2}$, which is $0.4 \%$ of the total land area of the Japanese Archipelago
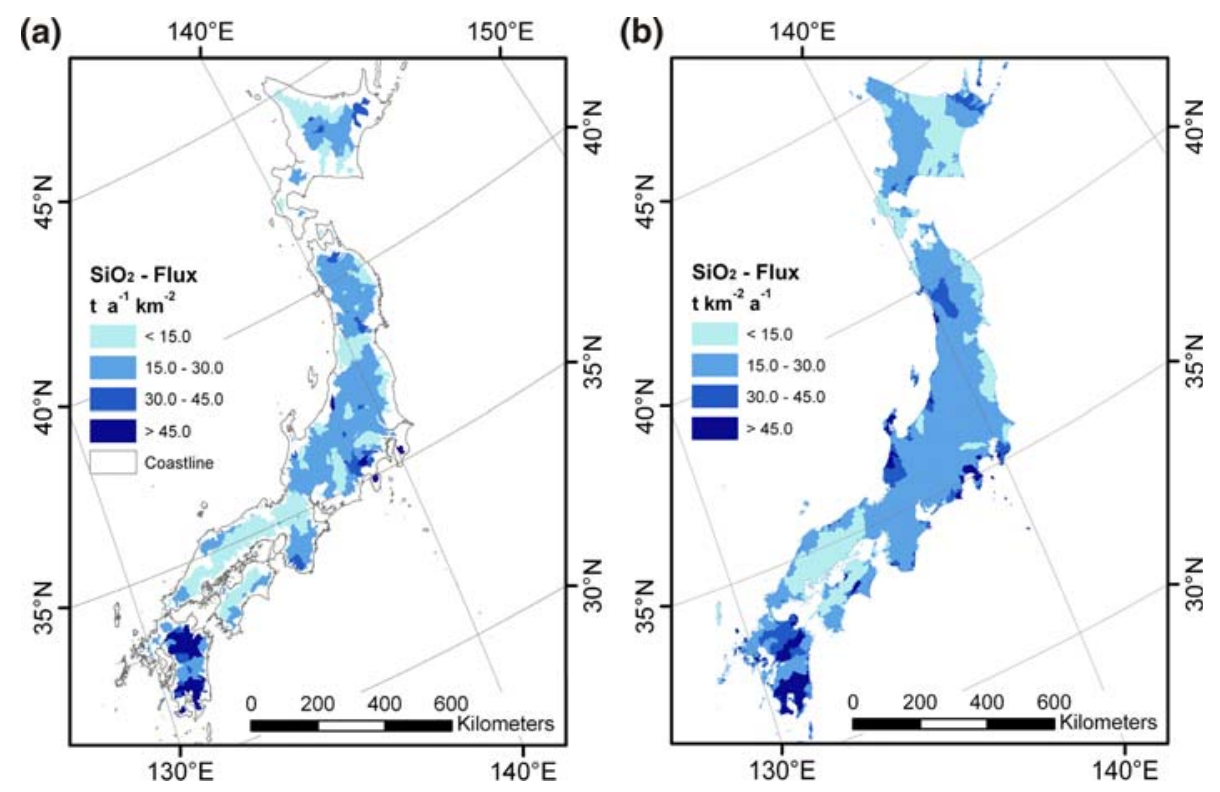

calculate average annual temperature for each basin. Furthermore temperature was corrected by $-0.0053 \mathrm{~K} \mathrm{~m}^{-1}$ altitude to represent elevation differences (cf. Schmarnow et al. 1982). The difference between actual SRTM altitude and elevation of each original temperature grid cell $\left(10^{\prime}\right)$ was used to calculate the elevation corrected mean temperature. Results were visually evaluated and even though grid boundaries are still visible, elevation corrected data (based now on the SRTM grid resolution) are now approaching each other at grid boundaries (Fig. 2d).

Atmospheric silica deposition was calculated using twelve stations representing the regional differences within Japan. Data were interpolated and average DSi atmospheric deposition rates for each catchment were calculated by applying regionalized precipitation data from over 150 atmospheric deposition monitoring stations using the product of precipitation and calculated local DSi concentration in atmospheric deposition. References for data used are given in Appendix A.

Soil data information for Japan with a resolution of $5^{\prime}$ were derived from Batjes (2006).

\section{DSi-flux modeling technique}

The analysis of the data used and the modeling workflow is schematised in Fig. 5. Calculated DSi-fluxes for each of the 516 catchments did not show large differences between observed (uncorrected) fluxes and fluxes corrected for atmospheric deposition. Because this difference represents only $2 \%$ of observed fluxes the originally observed fluxes were maintained for further analysis. This decision is based on the possibility that our model framework may be applied to global modeling later because the normally provided hydrochemical data sets are not corrected for atmospheric silica deposition. However, in the future the relevance of the global contribution of atmospheric DSi to river DSi should by investigated more closely. In a first approach (Treguer et al. 1995) estimated it to be around $10 \%$.

After calculating the areal average of assumed 'firstorder' controls according to the literature (i.e., runoff, temperature, slope, elevation, and proportion of lithological classes, land cover classes and soil characteristics $(\mathrm{pH}$, soil depth and soil organic $\mathrm{C}$ content) for each of the 516 catchments correlation analysis was carried out between them and specific DSi-fluxes $\left(\mathrm{t} \mathrm{SiO}_{2} \mathrm{~km}^{-2} \mathrm{a}^{-1}\right)$ for catchments dominated by one lithological class (i.e., one class covering $>60 \%$ of the catchment area).

In addition, scatter plot analyses were used to detect significant linear or nonlinear relationships between assumed first-order controls and DSi-fluxes. In this way lithology, runoff, slope and temperature were identified as potential predictors within the emphasized empirical model. Even though temperature correlates in general with slope (due to increasing slope in areas of high elevation) it does not show a clear correlation with DSi-flux for most lithological classes. Scatter plots relevant for analysis are presented in Appendix B.

Based on the results of the pre-analysis, several multivariable prediction functions for specific DSi-flux were tested, using the total data set of 516 catchments. Specifically, three prediction equation types were tested to calculate specific flux (SF) of DSi: 


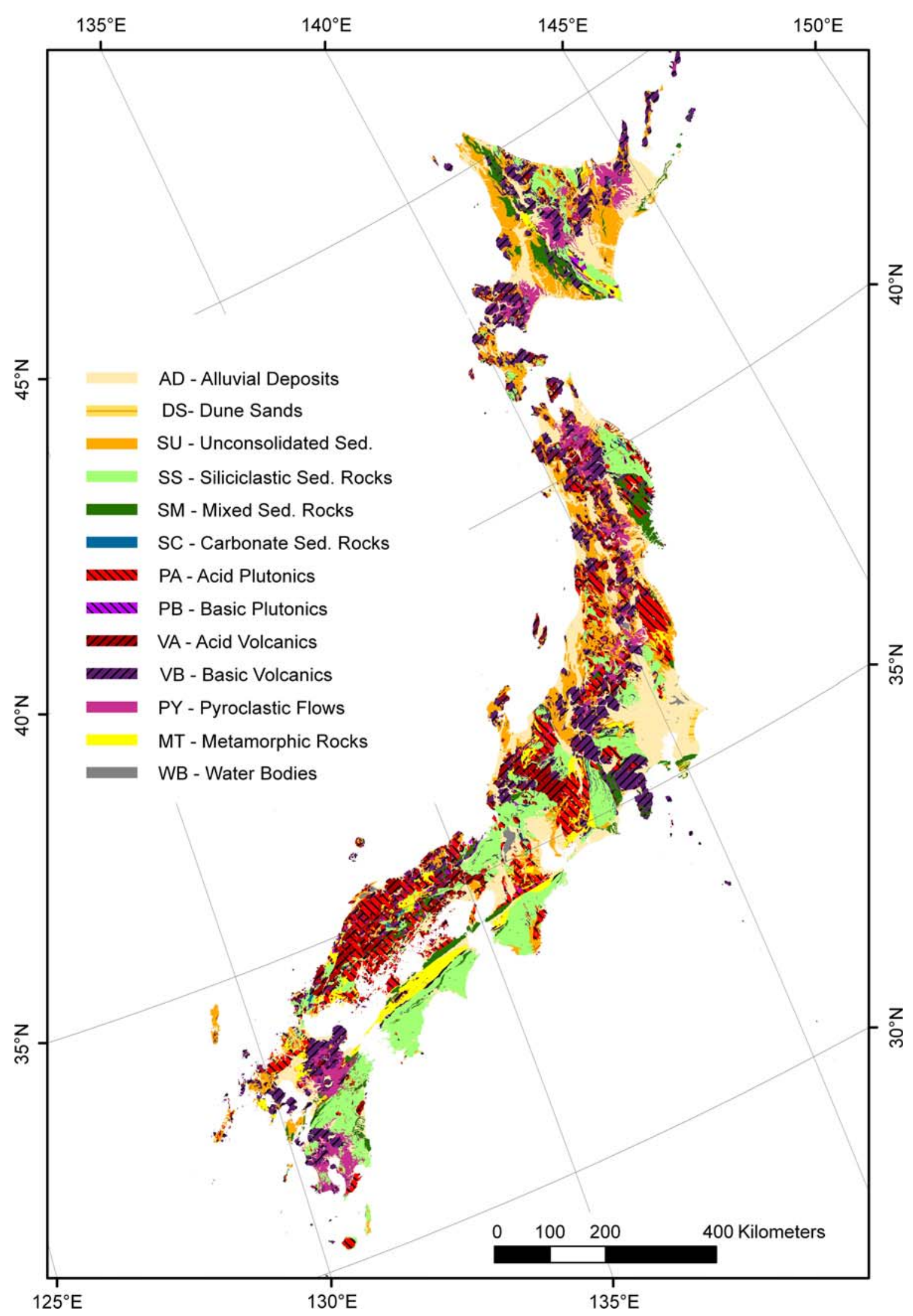

Fig. 4 Lithological map of Japan, derived from the vector-based geological map of Japan $(1: 1,000,000)$ (Hartmann 2008) 


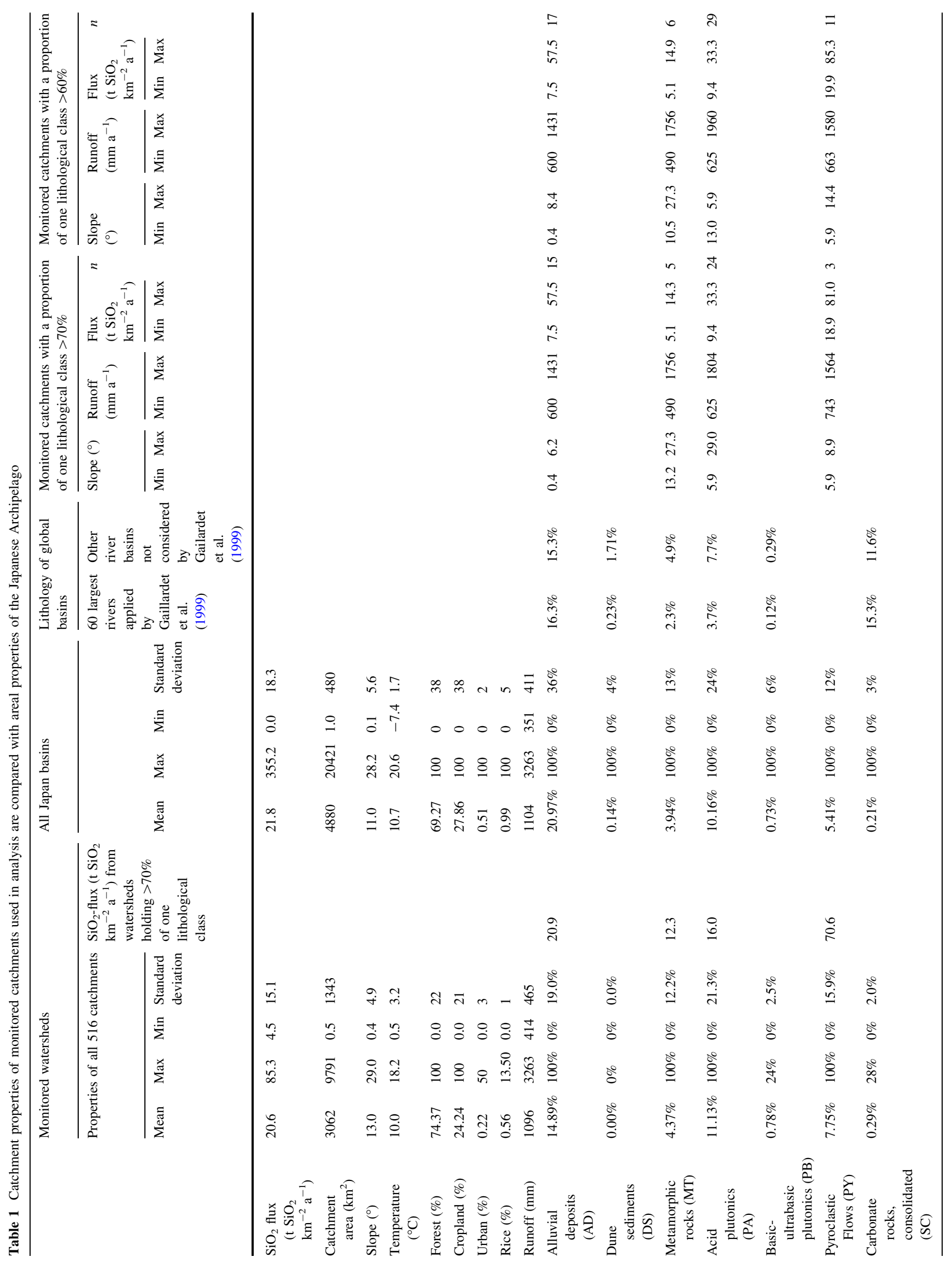




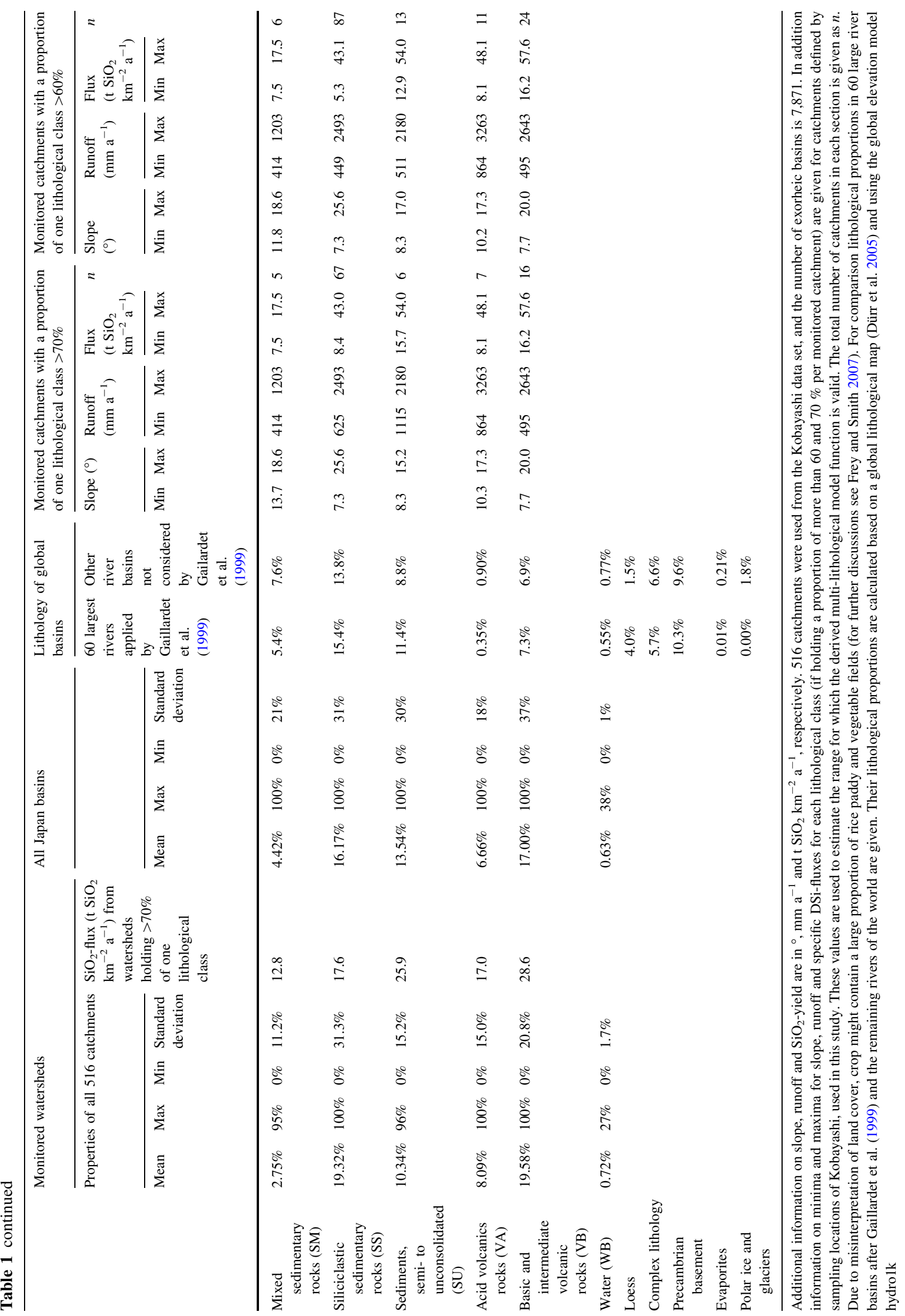




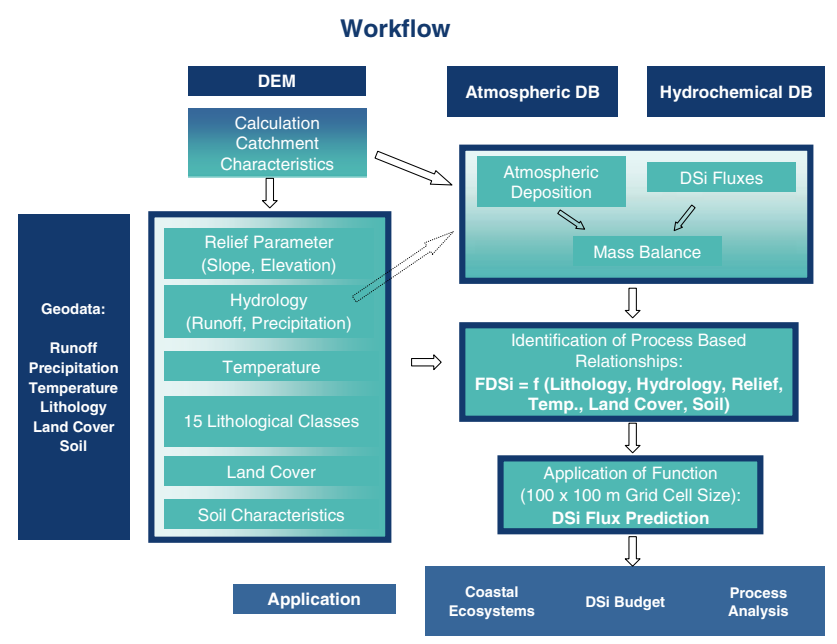

Fig. 5 General workflow of the modeling framework. Note that due to the small contribution of atmospheric deposition, uncorrected river DSi-fluxes were used for modeling

$$
\mathrm{SF}(\mathrm{DSi})=\mathrm{b}_{0}\left(L_{1} s^{b 11} q^{b 12}+L_{2} s^{b 21} q^{b 22}+\cdots+L_{n} s^{b n 1} q^{b n 2}\right)
$$

$\mathrm{SF}(\mathrm{DSi})=b_{0}\left(L_{1} s^{b 11}+L_{2} s^{b 21}+\cdots+L_{n} s^{b n 1}\right) q^{b 1}$

$\mathrm{SF}(\mathrm{DSi})=b_{0}\left(b_{1} L_{1}+b_{2} L_{2}+\ldots+L_{n}\right) q^{b q} s^{b s}$

$L_{x}$ is the proportion of each lithological class $x$ in a catchment, $s$ represents the average slope in degrees and $q$ the average runoff in $\mathrm{mm} \mathrm{a}^{-1} . b_{x y}$ are parameters which were estimated by nonlinear regression analysis using the Levenberg-Marquardt technique, implemented in the statistical software package Statistica 8.0 (Statsoft).

Note, that in lithologically heterogeneous regions, like Japan, a mono-lithological approach (one lithology representing the catchment) is bound to fail, as only a few watersheds are characterized by one lithology. Even the number of catchments being at least dominated by one lithology (i.e., reaching $60-70 \%$ of the catchment area) is very low (Table 1). The idea of the 'multi-lithological' lumped model approach is to estimate the contribution of each lithological class to total catchment DSi-fluxes according to identified first-order controls (i.e., predictors).

The design of the equations for the lumped multi-lithological model is process based, incorporating knowledge from previously identified relationships between potential controlling factors and DSi-fluxes (see "Discussion"). Basically the positive correlation between runoff and specific DSi-fluxes, previously reported by Bluth and Kump (1994) for other regions, was included, emphasizing differences for each lithological class. Slope, for example is in general inversely correlated with DSi-fluxes in catchments

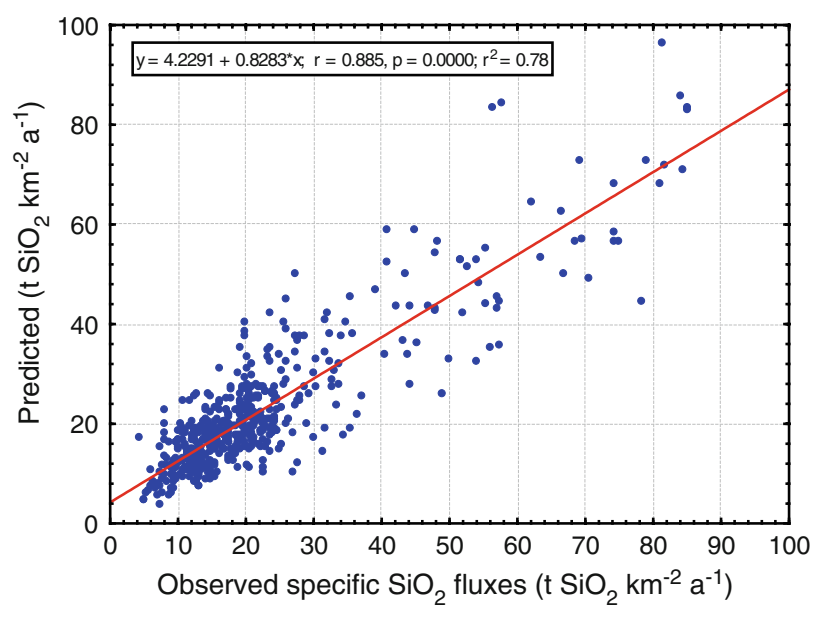

Fig. 6 Observed versus predicted specific DSi-fluxes for the 516 catchments using the averages of the calculated $b_{x y}$ parameters after conducting 1,000 times random sampling are presented (Table 2)

because with increasing slope, reaction rates per volume of water with mineral surfaces or influence of biology are decreasing.

We also tested variations of Eqs. 1-3, to include temperature, represented by an Arrhenius-term ' $\left.e^{(b t} T\right)$,, and land cover proportion, or to substitute slope by one of these. However, only for two functional relationships tested (Eq. 1 and 2), all estimated b-parameters passed test statistics according to the 5\% significance criterion. The highest correlation coefficient $(r=0.88)$ between predicted and observed fluxes (Fig. 6) is achieved by Eq. 1. All lithological classes listed in Table 1 were included into the prediction equations with the exception of dune sands, carbonates and basic plutonic rocks, as their proportion on the training catchments is very small only $(0.0,0.4$ and $0.8 \%$, respectively). Including them caused additional noise and the quality of the model decreased.

To evaluate the significance of the identified functional relationship, random sampling of the 516 catchments and their properties lithology, runoff and slope was carried out, choosing each time $80 \%$ of the total data set. The $b$-parameters were recalculated 1,000 times according to Eq. 1 in this way. Resulting average $b_{x y}$-parameters (Table 2) were then applied to predict DSi-fluxes on exorheic catchments of Japan. These catchments and their properties were calculated using ArcGIS 9.2. In total, 122,000 basins were differentiated, but most are very small, located along the coastlines. For technical reasons, all those coastline basins $(\sim 114,000)$ with $<1 \mathrm{~km}^{2}$ were combined into one catchment representing $3.2 \%$ of the total area of the Japanese Archipelago; 7,871 larger basins remained. 
Table 2 Average estimated $b$-parameters for runoff and slope after 1,000 times random sampling of the data set

\begin{tabular}{|c|c|c|c|c|c|c|c|c|}
\hline & Mean & Median & $\begin{array}{l}\text { Standard } \\
\text { deviation }\end{array}$ & Minima & Maxima & 25 th $\%$ & 75 th $\%$ & Valid $n$ \\
\hline b0 & 0.05 & 0.05 & 0.01 & 0.02 & 0.12 & 0.04 & 0.06 & 1,000 \\
\hline AD slope b11 & -0.07 & -0.06 & 0.05 & -0.28 & 0.03 & -0.09 & -0.03 & 1,000 \\
\hline $\mathrm{AD}$ runoff $\mathrm{b} 12$ & 0.88 & 0.88 & 0.04 & 0.74 & 1.02 & 0.86 & 0.91 & 1,000 \\
\hline MTslope b21 & -0.81 & -0.78 & 0.22 & -1.63 & 0.23 & -0.87 & -0.70 & 1,000 \\
\hline MTrunoff b22 & 1.05 & 1.04 & 0.08 & 0.65 & 1.35 & 1.01 & 1.08 & 1,000 \\
\hline PA slope b31 & -0.01 & -0.01 & 0.08 & -0.27 & 0.34 & -0.06 & 0.04 & 1,000 \\
\hline PA runoff $b 32$ & 0.83 & 0.83 & 0.05 & 0.65 & 1.01 & 0.80 & 0.86 & 1,000 \\
\hline Py slope b41 & -0.35 & -0.35 & 0.09 & -0.73 & -0.14 & -0.40 & -0.29 & 1,000 \\
\hline Py runoff b42 & 1.11 & 1.11 & 0.04 & 0.99 & 1.26 & 1.08 & 1.13 & 1,000 \\
\hline SM slope b51 & -2.06 & -2.13 & 1.47 & -44.09 & 1.16 & -2.29 & -1.92 & 1,000 \\
\hline SM runoff b52 & 1.60 & 1.64 & 0.40 & 0.39 & 12.12 & 1.55 & 1.69 & 1,000 \\
\hline SS slope b61 & -0.84 & -0.84 & 0.14 & -1.30 & -0.34 & -0.93 & -0.75 & 1,000 \\
\hline SS runoff b62 & 1.12 & 1.13 & 0.06 & 0.89 & 1.31 & 1.09 & 1.17 & 1,000 \\
\hline SU slope b71 & -0.12 & -0.13 & 0.19 & -0.84 & 1.81 & -0.22 & -0.04 & 1,000 \\
\hline SU runoff b72 & 0.86 & 0.87 & 0.09 & 0.04 & 1.08 & 0.81 & 0.91 & 1,000 \\
\hline VA slope b81 & -1.18 & -1.06 & 0.56 & -4.62 & 2.43 & -1.21 & -0.96 & 1,000 \\
\hline VA runoff b82 & 1.21 & 1.17 & 0.21 & -0.17 & 2.48 & 1.13 & 1.21 & 1,000 \\
\hline VB slope b91 & -1.26 & -1.25 & 0.16 & -2.09 & -0.77 & -1.36 & -1.15 & 1,000 \\
\hline VB runoff $b 92$ & 1.35 & 1.35 & 0.07 & 1.15 & 1.72 & 1.31 & 1.40 & 1,000 \\
\hline
\end{tabular}

For comparison median, standard deviation, minima, maxima and quartiles are given. Each parameter is significant on the 5\% $p$ value and $b$ parameters are normally distributed in each case, indicated by the narrow ranges between mean and median values

\section{Results}

Regional settings

Japan is a typical island arc, located at the boundaries of three tectonic plates (Pacific, Eurasian and the Philippine). It is characterized by high proportions of volcanic rocks (classes VA, VB, PY, see Table 1). Acid plutonics (PA), siliciclastic sedimentary rocks (SS) and unconsolidated sediments (AD and SU) are other major lithological classes. Carbonate rocks occur on only $0.3 \%$ of the area. The average slope of the exoreic basins is $11^{\circ}$, with maximal values of about $29^{\circ}$ in areas characterized by high proportion of sandstones, volcanics, plutonics or metamorphics. Properties of the 516 training catchments are only slightly different from those of the entire Japanese Archipelago, and hold an average slope of $13^{\circ}$. According to the land cover data used here, Japan is covered to $69.3 \%$ of forests, $27.9 \%$ of crop land, and a surprisingly small proportion of rice fields $(1 \%)$ and urbanized areas $(0.5 \%)$. A discussion on land cover distribution is provided below. For the 516 training catchments, land cover proportions are $74.4,24.2,0.6$ and $0.2 \%$, respectively. The average runoff amounts to $1104 \mathrm{~mm} \mathrm{a}^{-1}$, with maxima of up to $3,200 \mathrm{~mm} \mathrm{a}^{-1}$ in regions of Honshu facing the Sea of
Japan, Wakayama (middle part of southern Honshu), East Shikoku and southeast of Kyushu.

The typical basin size of Japanese river systems is rather small and steep, with a small basin size because of the specific morphology of the Archipelago (Table 1). Residence time of the water is, therefore, low which reduces the capability of diatoms to transfer DSi into amorphous silica (ASi). Only a few larger lakes exist that could retain dissolved silica as indicated by the small area of water bodies (Table 1).

\section{Observed DSi-fluxes}

Sampling locations of Japanese rivers in this study are given in Fig. 1, representing mostly the major islands Honshu, Hokkaido, Kyushu and Shikoku. Averages for DSi-fluxes, lithology, runoff, slope, temperature and land cover and the areas covered by monitoring are listed in Table 1. The average specific DSi-flux from the 516 catchments (20.6 $\mathrm{t} \mathrm{SiO}_{2} \mathrm{~km}^{-2} \mathrm{a}^{-1}$ ) is 6.2 times higher than the world average $\left(3.3 \mathrm{t} \mathrm{SiO}_{2} \mathrm{~km}^{-2} \mathrm{a}^{-1}\right)$, underlining that Japan is hyperactive with respect to DSi-fluxes. Atmospheric contribution of soluble $\mathrm{Si}$ is minor if compared to DSi mobilized by weathering ( $2 \%$ of fluvial DSi-fluxes). This low proportion-if compared to global estimates of 
10\% (Treguer et al. 1995) — can be attributed to the high weathering rates of Japan.

Relations between proposed first-order controls and DSi-fluxes

The dominant influence of lithology is revealed by average specific DSi-fluxes for catchments with one dominant (i.e., $>70 \%$ of area) lithological class (Table 1). Highest specific DSi-fluxes are found for catchments dominated by volcanics and unconsolidated sediments (Appendix B). For volcanics this is in accordance with previous research on weathering rates (Dessert et al. 2003; Rad et al. 2006).

Univariate correlation and scatter plot analyses between first-order controls and DSi-flux for each lithological class revealed that for most classes reliable functional relations with DSi-fluxes exist only for runoff and slope (Appendix
B). Regressions plotted in Appendix B are influenced by noise of other lithological classes characterized by different specific DSi-fluxes. While runoff shows a positive correlation with DSi-fluxes for each lithological class (caused in part by including runoff in the flux calculation), relations between DSi-flux and slope are characterized by a negative regression for most lithological classes as would be expected. In case of positive regressions (lithological classes AD, SS, PA and SM), correlation coefficients were not significant on the $p$ level of $15 \%$. For some relations with a positive correlation between slope and DSi-fluxes, like mixed sedimentary rocks (SM), and admixture with 'contamination' due to significant amounts of volcanics is the explanation. Negative correlation is observed after omitting catchments showing significant proportions of volcanics for the class SM. Note, that volcanic classes PY and VB are in general characterized by high specific DSifluxes.
Fig. 7 Specific DSi-fluxes for fixed slope and variable runoff for mono-lithological conditions. DSi-fluxes were calculated using the $b$-parameters estimated by Eq. 1 (Table 2), based on the principal equation $F(\mathrm{DSi})=b_{0} s^{b s} q^{b q}$, where $s$ is slope, $q$, runoff, $b s$ the parameter for slope and $b q$ the parameter for runoff. Typical slope ranges (rounded to next $5^{\circ}$ ) for each lithological class if its areal proportion is higher than $60 \%$. $V B$ 5-25; $P Y$ 5-15 VA 10-20'; MT 10-30 ; PA 5-30'; SM 10-20 ; SS 5-30 $S U$ 5-20 $; A D 5-15^{\circ}$. Note that the scales for DSi-flux are different for each figure. Full names of lithological class abbreviations are supplied in Table 1
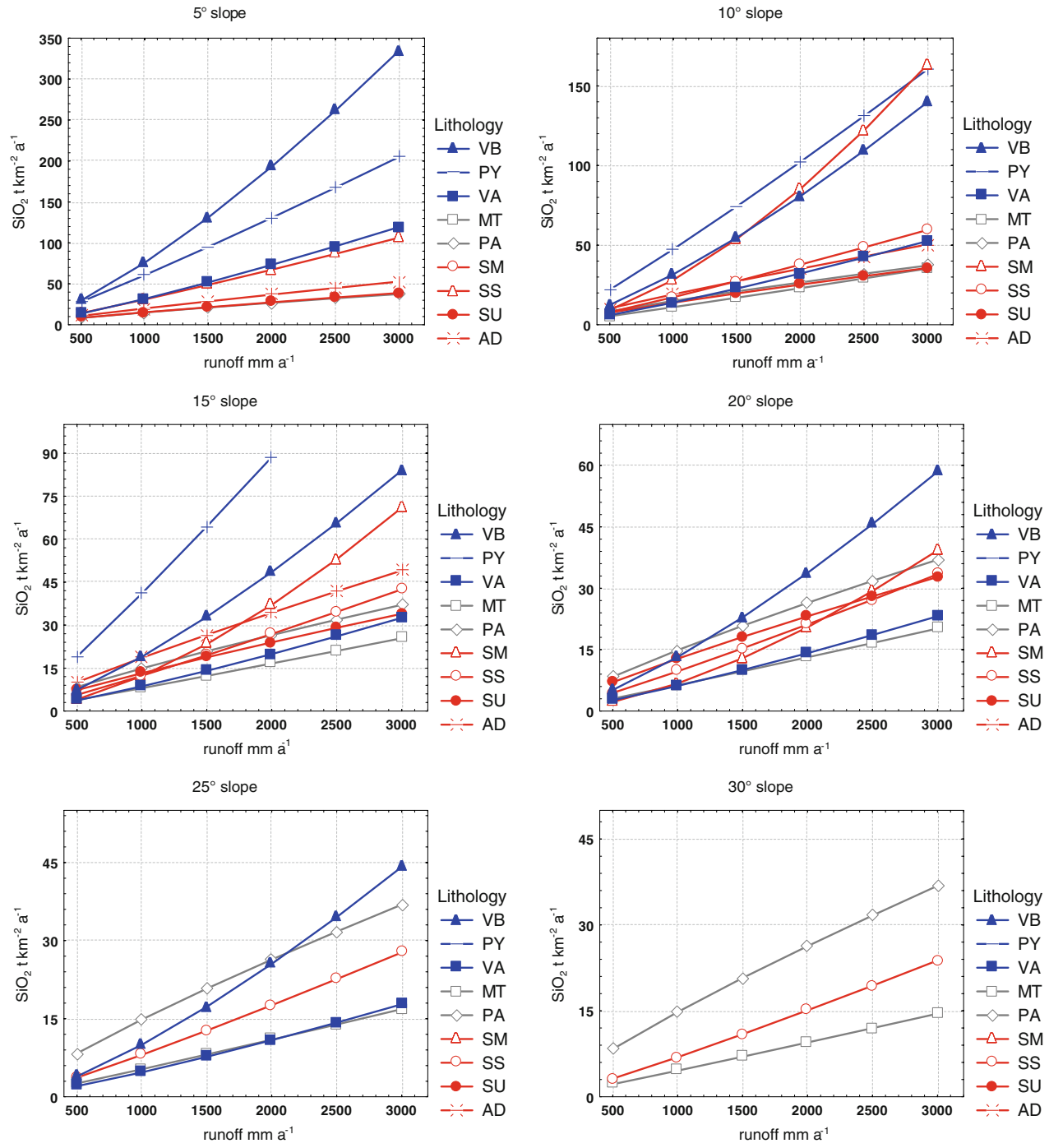
Fig. 8 Specific DSi-fluxes for fixed runoff and variable slope for mono-lithological conditions. DSi-fluxes were calculated using the $b$ parameters estimated by Eq. 1 (Table 2) based on the principal equation $F(\mathrm{DSi})=b_{0} s^{b s} q^{b q}$, where $s$ is slope, $q$, runoff, $b s$ the parameter for slope and $b q$ the parameter for runoff.

Typical slope ranges (rounded to next $5^{\circ}$ ) for each lithological class if its areal proportion is higher than $60 \%$. $V B$ 5-25 ; $P Y$ 5-15'; VA 10-20 ${ }^{\circ}$; MT 10-30 PA 5-30'; SM 10-20 ; SS 5-30 ; SU 5-20 ; AD 5-15 .

Note that the scales for DSi-flux are different for each figure. Full names of lithological class abbreviations are supplied in Table 1
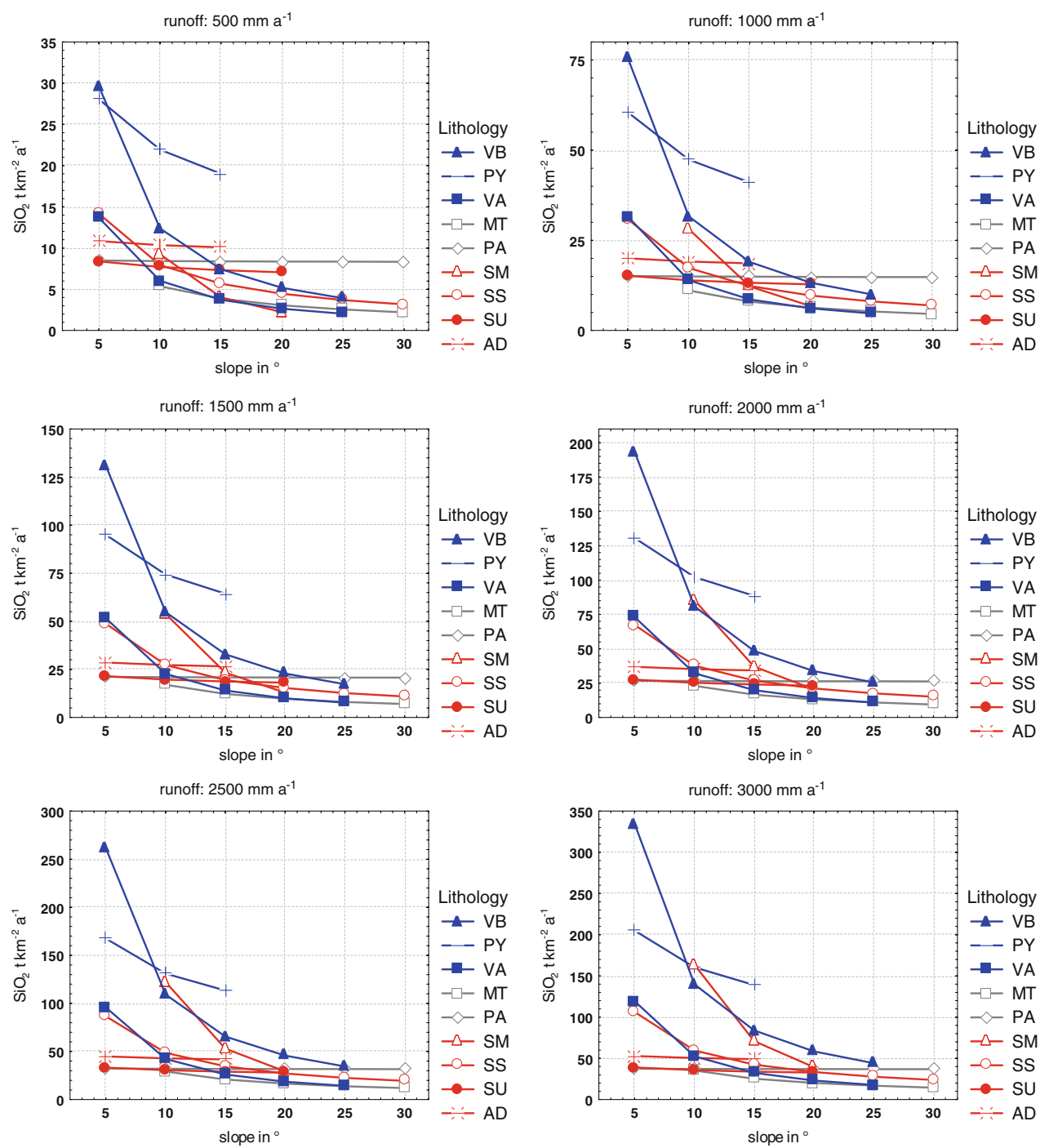

Some individual temperature and DSi-flux correlations proved to be significant; others were not because of too many outliers. The significant multiple correlation of temperature with slope and runoff (Figs. 7, 8), suggests that temperature can be substituted in part by these two factors (Fig. 9). Specifically in elevated areas slope and temperature correlate highly.

Other factors, such as land cover and soil characteristics did not show significant univariate correlations and/ or clear patterns with specific DSi-fluxes for the majority of lithological classes. Often scatter plot analysis revealed complex patterns, indicating some irregular influence as for example in case of forest proportion (Fig. 10a). Thus, no basic functional relationship exists for these factors in form of a simple term in a prediction equation. Note, that 'first-order' controls in prediction equations can only be parameters with previously identified significant correlations and applicable functional relations that were accepted after pre-analysis. In addition, a detailed analysis of land cover reveals that specifically in elevated regions of Honshu, crop and rice fields are not always represented appropriately. For example, in elevated areas of the Japanese Alps sometimes crop is displayed as land cover where no agricultural activity is evident from satellite images or maps. For further discussion about this problem on recent land cover data see Frey and Smith (2007).

These results show that the mono-lithological approach would leave only a few catchments for analysis, and additional "noise" due to other first-order factors would be the consequence. Therefore, the proposed 'multi-lithological' approach is necessary.

Predicted DSi-fluxes: the control of runoff and slope

According to the estimation technique, prediction equations should only be applied if catchments or basin characteristics for slope or runoff are within the typical 


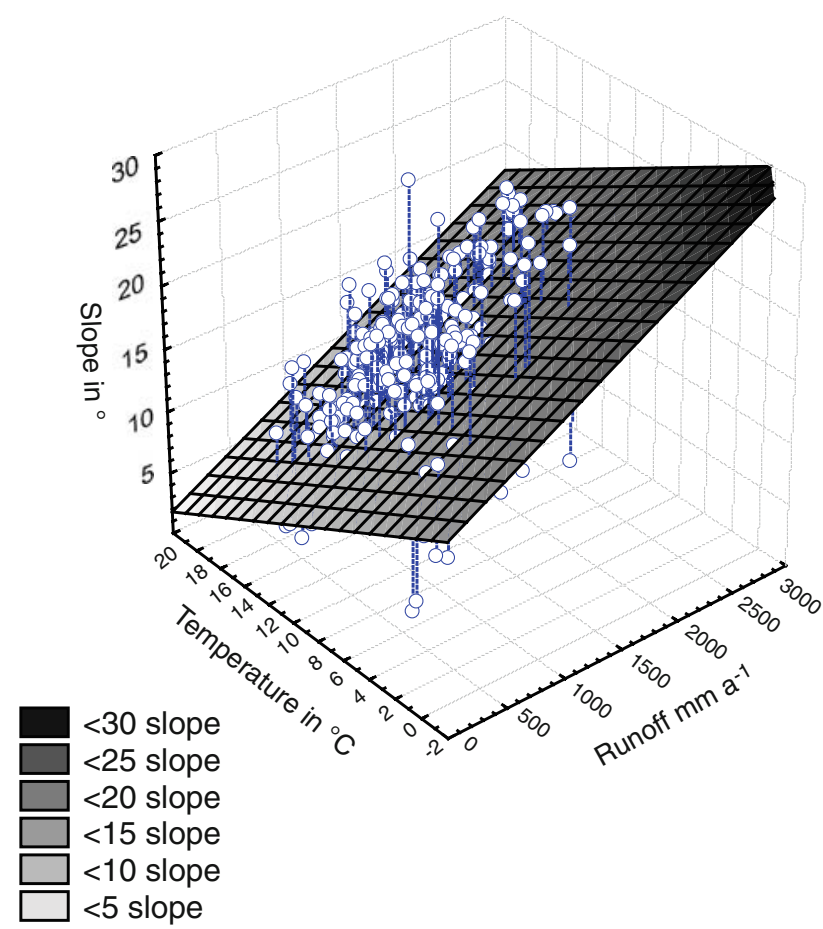

Fig. 9 A significant multiple linear correlation exists between slope, runoff and temperature for the 516 analyzed catchments $(r=0.56)$

ranges for each lithological class. To retain appropriate ranges for slope and runoff, minima and maxima of average slopes and runoff values for each training catchment were reviewed for the case that one lithological class holds more than $60 \%$ proportion of a catchment (Table 1). Identified minima and maxima are assumed here to represent valid ranges for prediction Eq. 1 in the first instance.

Very low $b$-parameters indicate (Table 2) that specific DSi-fluxes are sensitive to slope, specifically for lithological classes SM, VB and VA. For a slope $<7^{\circ}$, specific DSi-fluxes of VB and SM are exceeding those of pyroclastics for runoff $>500 \mathrm{~mm}$ (Figs. 7, 8). For a number of reasons, including mineral composition, grain size and hydrogeological properties, one should assume that specific DSi-fluxes from non-pyroclastics don't exceed specific DSi-fluxes from pyroclastics, under similar runoff and low slope conditions. Because of this, the slope-factor $\left(s^{b x y}\right)$ for lithological classes SM and VB in Eq. 1 was forced to be at least $7^{\circ}$ for comparison with the 'not-forced' results. This approach is called 'forced approach' below. The total area affected by this forcing amounts to only $2.4 \%$ of the area of Japan. Runoff parameters appear not to be affected by this problem. This might be attributed to the observation that runoff $b$-parameters are close to 1 in most cases. Thus no forcing was applied for runoff parameters.

The total specific DSi-flux using the forced model amounts to $21.84 \mathrm{t} \mathrm{SiO}_{2} \mathrm{~km}^{-2} \mathrm{a}^{-1}$ or $8.18 \times 10^{6} \mathrm{t} \mathrm{SiO}_{2} \mathrm{~km}^{-2} \mathrm{a}^{-1}$

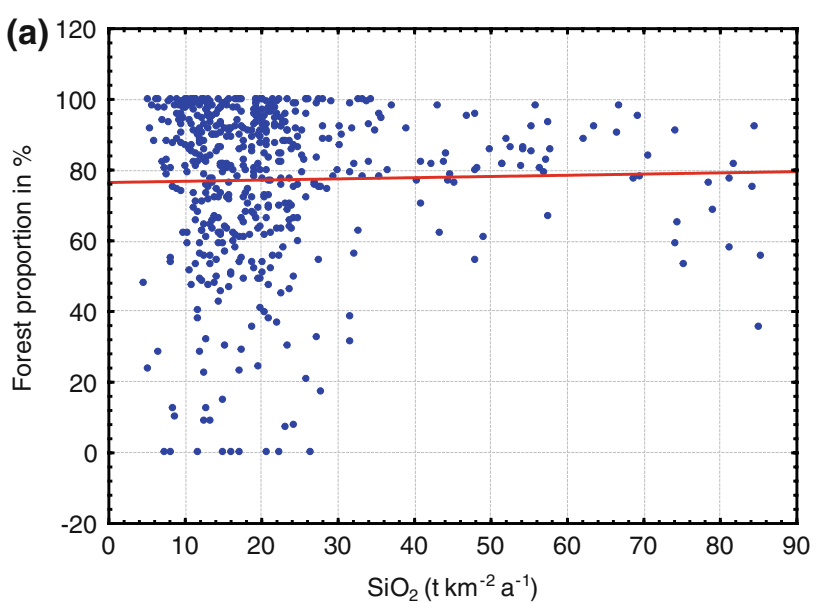

(b)

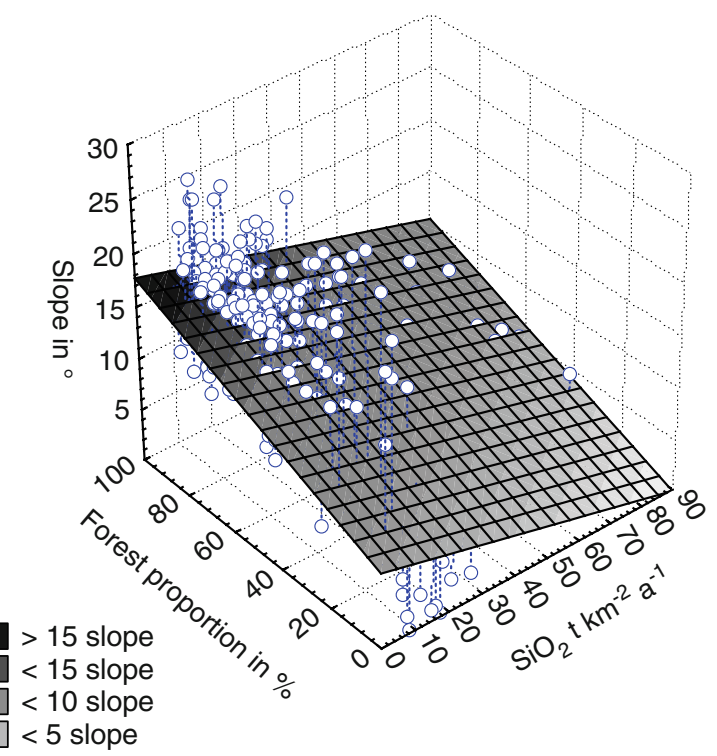

Fig. 10 Relation between specific DSi-fluxes and the land cover type forest (a), and relations between specific DSi-fluxes, slope and the land cover type forest $(r=0.53)(\mathbf{b})$

as total discharge from Japan. By forcing the factor slope, $4.19 \%$ of the total modeled area is affected. An area of $37,615 \mathrm{~km}^{2}$ (10\% of Japan) has a specific DSi-flux of $>33 \mathrm{t} \mathrm{SiO}_{2} \mathrm{~km}^{-2} \mathrm{a}^{-1}$ and can be defined as hot spot area, according to the classification of Meybeck et al. (2007).

In case no forcing on the slope factor was applied, i.e., allowing for what we think are unreliable high specific DSi-fluxes from the lithological classes $\mathrm{SM}$ and $\mathrm{VB}$, then the average specific DSi-flux is $23.49 \mathrm{t} \mathrm{SiO}_{2} \mathrm{~km}^{-2} \mathrm{a}^{-1}$ or $8.88 \times 10^{6} \mathrm{t} \mathrm{SiO}_{2} \mathrm{~km}^{-2} \mathrm{a}^{-1}$ in total. This is $8.4 \%$ higher compared to the forced approach. In this case 19 basins show a specific DSi-flux $>1,000 \mathrm{t} \mathrm{SiO}_{2} \mathrm{~km}^{-2} \mathrm{a}^{-1}$ and eight even $>5,000 \mathrm{t} \mathrm{SiO}_{2} \mathrm{~km}^{-2} \mathrm{a}^{-1}$. Applying the forced approach, only 35 basins show $>100 \mathrm{t} \mathrm{SiO}_{2} \mathrm{~km}^{-2} \mathrm{a}^{-1}$ and six $>150$ with a maximum at $355 \mathrm{t} \mathrm{SiO}_{2} \mathrm{~km}^{-2} \mathrm{a}^{-1}$. Thus, 
by applying the forced approach modeled fluxes are within reported ranges from volcanic regions.

According to the process-based Eq. 1, the lumped model approach resulted in a highly significant correlation $(p<0.0001)$ between observed and predicted specific DSifluxes (Fig. 6). Residuals between predicted and observed specific DSi-fluxes are normally distributed, supporting the significance of the model. In addition, it was tested if temperature could be integrated into the model equation by (1) replacing slope with temperature or (2) including temperature applying a modification of the Arrhenius law (White et al. 1999; Dessert et al. 2003). In both cases correlation coefficients between predicted and observed specific DSi-fluxes were less and/or estimated $b$-parameters were not significant on the $5 \%$ level. Because temperature displays a multiple correlation with runoff and slope, part of the temperature information is included in the prediction equation (Fig. 9).

In Japan, a certain spatial correlation between land cover class, lithology and slope exists. However, relations between land cover and DSi-fluxes can not easily be described by simple functional relationships and information on forest is to some part incorporated in the parameter slope (Fig. 10a/b). The additional inclusion of land cover lowered the prediction quality of the model.

The mean values of retrieved $b_{x y}$-parameters from the model approach after sampling the data set randomly 1,000 times is given in Table 2 . Higher variability of slope $b$-parameters $(-0.01$ to -2.06$)$ compared to runoff $b$-parameters ( 0.83 to 1.6 ) indicates a stronger control of slope than runoff in specific cases and is discussed below. Specifically, unconsolidated sediments are characterized by comparatively high slope $b$-parameters $(-0.35$ to $-0.07)$. Slope $b$-parameters close to zero are indicating that runoff is the major control in these cases. Note that for a slope $b$-parameter close to zero, like for $\mathrm{AD}, \mathrm{SU}$ and PA the expression for slope $s^{0}=1$ may be applicable. Volcanic rocks (VB \& VA) and mixed sediments (SM) are characterized by lowest slope $b$-parameters $(<-1)$. In these cases less silica is mobilized with steeper slope, if runoff stays fixed.

Runoff $b$-parameters close to 1 (e.g., MT) indicate a nearly linear relationship between DSi-fluxes and runoff. The higher a runoff $b$-parameter is the higher is the influence of runoff on DSi-fluxes for a certain lithological class. Mixed sedimentary rocks (SM), acid volcanics (VA) and basalts/intermediate volcanics (VB) have lowest slope $b$-parameters and highest runoff $b$-parameters. Thus they are very sensitive to changes in one of these factors with respect to specific DSi-fluxes.

The ranges of slope and runoff $b$-parameters per lithological class are reflecting to some part different diagenetic settings and/or mineralogical composition and properties.
They can be divided roughly into three classes: (1) hard rocks (MT, SS), (2) volcanics (VA, VB and PY) and (3) unconsolidated (non-volcanic) sediments (AD, SU).

Figures 7 and 8 represent differences in sensitivity of DSi-fluxes due to variability in slope and runoff for each applied lithological class and the typical ranges of slope observed in the 516 catchments (compare Table 1). If runoff stays fixed the DSi-fluxes from VB and SM can exceed the ones from PY for slope values $<\sim 7^{\circ}$ (Fig. 8). This could be a relict from applied catchment data, as the minimum slope for catchments holding more than $60 \%$ VB and SM are characterized by a slope of $7.6^{\circ}$ and $12^{\circ}$, respectively. In addition, the lithological class SM has a low areal proportion in Japan (Table 1). Predicted DSifluxes for not monitored catchments with slopes $<7^{\circ}$ slope may thus not be within a valid range. This is supported by the observation that those of the monitored catchments that are dominated by pyroclastics normally show highest DSi-fluxes. However, it is probable that low-slope areas mapped as other volcanics have significant amounts of pyroclastics that are not mapped as individual units. Cross checking with the lithological map of Japan reveals that the areas of class SM often occur near volcanics. Thus, the estimates of $b$-parameters for VB and SM may be influenced by this vicinity with pyroclastics. Because of this it is important to consider valid slope ranges for each lithology. This problem is smaller for runoff, as estimated $b$-parameters are in general close to 1 and do not show the large variability of slope $b$-parameters. Valid ranges are especially important, in case identified prediction equations are applied spatially explicit to areas not monitored. It is important to note that due to the bivariate correlation between slope and runoff $(r=0.40$ for the total data set) the impact of value changes by one of those predictors on DSi-fluxes cannot be quantified easily. However, because of the design of the prediction equation (Eq. 1), it can be assumed that the combined effect of slope and runoff on DSi-fluxes from each lithological class is appropriately represented for settings of the Japanese Archipelago. This is supported by the significance of the prediction equation $(p<0.0001)$. It is likely that the presented prediction equation does not represent a globally applicable DSi-flux prediction model and further research should try to shed more light on this issue (see Discussion).

\section{Discussion}

General discussion

The lumped model approach used here was previously applied on a regional and global scale for other riverine 
components than DSi, like suspended matter, alkalinity, organic carbon, nitrogen and phosphorus (Ludwig et al. 1996; Amiotte-Suchet et al. 2003; Bouwman et al. 2005; Seitzinger et al. 2005; Beusen et al. 2005). Results from our study suggest that the multi-lithological lumped model approach is also applicable to predict DSi-fluxes on a regional scale and thus probably on a global scale as well. However, in the latter case, scale issues like for slope or mass transfer processes like uptake of DSi by diatoms in lakes need to be addressed.

For the first time a vector-based lithological map was applied to a multi-lithological approach. In addition, it was aspired not to use a purely statistical approach like multiple linear regression for retrieving a prediction equation (cf. Beusen et al. 2005). Instead, the design of the empirical prediction equation addresses differences in weatherability for each lithological class within each training catchment, hydrological flow processes as well as weathering and transport limitation and is based on previous work on chemical weathering (cf. Bluth and Kump 1994; Gislason et al. 1996; Gaillardet et al. 1999; Moulton et al. 2000; Millot et al. 2002; Lyons et al. 2005). These publications emphasize to isolate the impact of relevant factors on chemical weathering.

Results from here introduced approach supports the hypothesis that functional terms (compare Eqs. 1-3) for each lithological class in prediction equations should not solely be additive, but should be of a multiplicative type for considered relevant predictors. This would allow representing combined influences of first-order controls (like runoff or slope) on DSi-fluxes from the terrestrial to the fluvial system. Additive terms may be appropriate if describing reservoir changes in training catchments, as e.g., plant uptake or lakes.

The overall design of Eq. 1 allows predicting DSi-fluxes for each lithological class in a catchment. Therefore, our approach differs from previous mono-lithological approaches (cf. Bluth and Kump 1994). The general formula identified here can be written for a mono-lithological approach, if applied spatially explicit at the same geodata resolution for slope, as follows:

$\mathrm{F}_{\mathrm{i}}(\mathrm{DSi})=\mathrm{b}_{0} \mathrm{~s}^{\text {bsi }} \mathrm{q}^{\text {bqi }}$.

While $i$ represents a lithological class, $s$ slope, $q$ runoff, $b_{0}, b s_{i}$ and $b q_{i}$ are the estimated $b$-parameters from Table 2.

Slope was introduced here as a further controlling factor on DSi-fluxes. This decision is supported by research on small Japanese catchments, showing that in steep watersheds event waters and subsurface waters are transported relatively fast to the draining river system, resulting in a relatively short contact time with fresh weatherable rocks or soils if compared to less steep environments (Sidle et al. 2000; Asano et al. 2003, 2004; Anazawa and Ohmori 2005; Asano and Uchida 2005; Kawai et al. 2006). Observed average slopes suggest that Japanese catchments are in general 'weathering-limited' and not 'transport-limited' (compare Bluth and Kump 1994; Anderson et al. 2007).

Even though we use only three 'first-order' controls (or predictors) on DSi-fluxes (i.e., lithology, runoff and slope) predicted DSi-fluxes correlate highly with measured catchments $(r=0.885)$. Including further factors resulted in a decreasing quality of the prediction model, and may be attributed to the typical settings of the Japanese Archipelago, the used geodata resolution and quality, as well as correlations among analyzed variables. For example, steep areas are dominated by forests and flat areas by agricultural activity or are urban areas. These flat areas are mostly located close to the coast and belong predominantly to lithologies $\mathrm{AD}$ or SU (compare Hartmann et al. 2006).

Because the sampling locations were mostly upstream of urban places it is assumed that our results represent DSifluxes not significantly impacted by urban areas. The 6.6 times higher than world average specific DSi-fluxes (according to the forced model approach) can be attributed partly to the tectonic setting of Japan as a volcanic island arc adjacent to subduction zones, indicated by spatial earthquake patterns (Dürr et al. 2005, 2008; Hartmann 2005). However, if the approach used here is applied to other regions or on a global scale, resulting $b$-parameters in the model equation will differ. This can be attributed to the observation that some regions with rather low slope are sometimes characterized by transport limitation instead of weathering limitation with respect to specific DSi-fluxes (cf. Bluth and Kump 1994; Kump et al. 2000). It is likely that further factors like land cover, lake retention or temperature need to be incorporated into a global prediction model. This is because those factors may not correlate significantly with factors applied in this study globally (or regionally), and therefore may partly substitute predictors used here (as, e.g., temperature in this study). In any case correlations among assumed controlling factors have to be analyzed.

The high proportions of volcanics suggest that not only the Japanese Archipelago but the entire "Ring of Fire" around the Pacific could be classified as hyperactive with respect to DSi-flux and silicate weathering. At least for Japan this hypothesis has been tested positively (cf. Dürr et al. 2008).

Discussion of model results

The DSi-flux model used by Bluth and Kump (1994) applied log-log functional relationships between specific 
DSi-flux and runoff for five lithological classes (basalt, granite, sandstone, shale and limestone), based on a mono-lithological approach. No differences between consolidated and unconsolidated sediments were made. The effects of other factors on DSi-fluxes were not included.

While using slope as an additional controlling factor, new insights into processes controlling DSi-fluxes on a regional scale are provided. Fluxes decrease with increasing slope for all analyzed lithological classes (Fig. 8), according to the $b$-parameters retrieved in Eq. 1 (Table 2). The influence of slope is lowest (low to not recognizable) for unconsolidated sediments (AD and SU) and acid plutonitcs (PA). Due to low values in slope $b$-parameters (b is close to 0 ) runoff remains the major important control/ predictor on DSi-fluxes for these lithological classes. In contrary, slope may cause variation in specific DSi-fluxes for volcanic lithological classes VB and VA by nearly a factor of 7-10 in case of high runoff $\left(>1,000 \mathrm{~mm} \mathrm{a}^{-1}\right)$ (Figs. 7, 8). Runoff values of more than $1,000 \mathrm{~mm} \mathrm{a}^{-1}$ are typical for the Japanese Archipelago (average $1,104 \mathrm{~mm} \mathrm{a}^{-1}$ ). Findings support the hypothesis that under high runoff conditions slope constitutes a stronger controlling factor on specific DSi fluxes than runoff for VA, VB, PY, SS and SM. This highlights the principal importance of uplifting of mountains or tectonic activity for DSi-fluxes.

Even though the influence of temperature and land cover on chemical weathering was identified in general (White et al. 1999; Moulton et al. 2000; Dessert et al. 2003), the incorporation of these factors into the model equation did not improve DSi-flux prediction quality. As discussed above, this may be attributed in part to the observed correlation between the factors slope, runoff, temperature and land cover. This correlation may result into a suppression of their influence in a prediction equation. However, it can not be concluded that these factors do not at all influence specific DSi-fluxes (cf. "Error discussion"). They may be incorporated in future approaches, if reliable functional relations can be identified for representing these factors as controls in a prediction equation. One possibility might be the application of multiple equations for distinguishable regions and recognizing valid ranges of estimated parameters for certain regions, or incorporation of seasonal effects (which were not analyzed here). However, in this case large training data sets are needed to retrieve reliable models. In the context of a prediction model as presented here the term 'first-order controlling factor' should be understood as 'predictor', because some variables possibly possess prediction potential but are represented in part by others and are thus not considered in the prediction equation.
Error discussion

\section{Lithology}

One of the difficulties in applying lumped model approaches is that average catchment characteristics are used for parameter estimation while some lithological classes are characterized by low abundance in training catchments. Because of this, prediction parameters, as for example for lithology SM may not be estimated appropriately. For some classes, like PB or SC no parameters could be identified due to this problem. The natural spatial correlation of some lithological classes, like PY and VB, influences the model outcome as well. In case of low catchment slopes, specific DSi-fluxes from lithological class VB may then exceed those from PY, which is in general not probable due to reasons provided above (cf. Rad et al. 2006). However, the number of catchments used for model development is high if compared to previous approaches, and test statistics support model and estimated parameter validity.

Further uncertainties arise because small scale spatial differences in mineral content of rocks are not covered by the general lithological classification scheme. Due to differences in dissolution kinetics of minerals spatial mineralogical differences may contribute to differences between observed and calculated specific DSi-fluxes.

\section{Runoff}

Because of data availability and resolution, runoff remains one of the three factors considered for model calibration which may contribute a significant noise to results. Unfortunately, no monthly runoff data for most of the sampling locations used by Kobayashi were available to calculate monthly fluxes in order to consider seasonality. We used the annual global runoff data set (Fekete et al. 2002) with a resolution of $0.5^{\circ}$ that was originally designed to represent global runoff. Thus, runoff may not fully represent local runoff at the time of sampling by Kobayashi. For the few available annual discharge data (Kobayashi 1960) a cross-check was conducted with the runoff data of Fekete et al. (2002). No large differences were observed and it was thus assumed that for this study the applied runoff data are sufficient. So far there are no data to represent differences between rain and snow that could dilute temperature effects or influence weathering rates because of, e.g., differences in soil infiltration or percolation patterns.

Japan has two seasonal precipitation maxima. One occurs during summer (Krishnan and Sugi 2001) in areas facing the Pacific Ocean (southern part of Honshu, Eastern Shikoku and Kyushu). The other occurs during winter in mountainous areas facing the Sea of Japan because air 
masses from Central Asia, originally cold and dry, gain water vapor supplied by a warm current intruding the Sea of Japan from the south. Some of this precipitation remains as snow until spring time.

\section{Hydrothermal activity}

Influence of hydrothermal activity was minimized by discarding sampling stations with elevated $\mathrm{Cl}$-concentration (see above). Influence of hydrothermal activity on the hydrochemistry of stream and spring water is assumed to be minor for all of Japan, but may be important on a local scale, specifically if seismotectonic processes trigger a substantial fluctuation in water chemistry (Hartmann et al. 2005; Hartmann 2006).

\section{Landcover and vegetation effects}

It is known that local DSi cycles are influenced by plant uptake of DSi, transforming DSi into phytoliths (Alexandre et al. 1997; Meunier et al. 1999; Conley 2002). The amount of DSi uptake by plants can be much larger than the mobilization of DSi by weathering (Alexandre et al. 1997; Meunier et al. 1999; Conley 2002) and much of the terrestrial amorphous silica (ASi) in form of phytoliths is recycled. Some of this ASi may be eroded and transported as suspended matter to the coastal zones. Data on $\mathrm{ASi}$ transported by rivers in Japan suggest that ASi (terrestrial and fluvial) can be assumed to be in the range of $1 / 5$ to $1 / 10$ of riverine DSi (Isaji 2003; Harashima et al. 2006). However, it can be assumed that the retention of DSi in plants is only relevant for the variability of fluvial DSi-fluxes if the catchment ecosystems are undergoing changes in their biomass (cf. Fulweiler and Nixon 2005), or if a significant change in phytolith dissolution rate occurs.

Furthermore, plants influence weathering processes positively and DSi plant uptake is correlated with available DSi concentration in groundwater and soil solution (Lucas 2001) thus linking it with underlying lithology. Vegetation also influences the water cycle and thus partly controls runoff. Due to these effects land cover is correlated with runoff and lithology (e.g., via relief characteristics induced by underlying lithology and tectonic activity). This correlation and the observation that vegetation distribution is often not correctly displayed by satellite-derived land cover data (Frey and Smith 2007) may make it difficult to improve the used lumped model approach by incorporating land cover as a prediction factor. However, scatter plot analysis revealed at least some relations between land cover and specific DSifluxes. For example, catchments characterized by high proportions of forest $(>50 \%)$ show on average highest specific DSi-fluxes (Fig. 10). However, due to the other factors influencing DSi-fluxes (Fig. 10) no clear case could be made for including land cover or forest proportion into the model equation. This may be because lithology, slope and runoff represent indirectly some information of land cover effects on DSi-fluxes for Japan. For example, areas dominated by unconsolidated sediments (AD and SU) have high land cover percentages of rice and crop land due to the rather flat slope. In addition, rice terraces and small ponds may be responsible for retention of certain amounts of DSi in form of ASi (cf. Ma et al. 1989; Ma and Takahashi 1989). It is interesting to note, that rice contains $4-20$ weight $\%$ of $\mathrm{SiO}_{2}$. However, due to Japan's wet climate it is assumed that some $\mathrm{ASi}$ is dissolved rapidly and released as DSi according to the seasonality of harvesting (Ma and Takahashi 1989). Nevertheless, some Si should be removed as ASi by rice harvesting. The tradition of burning rice straw in the original rice paddy field for nutrition after harvesting, may have limited this export. In recent years, this tradition is less and less practiced because of environmental concerns and legislations (personal communications with farmers).

\section{Temperature}

A positive correlation between temperature and fluvial DSi-fluxes was identified (Garnier et al. 2006). Such relation could therefore be implemented into the model. In fact, global studies on chemical weathering rates applied temperature as an important factor in models for basalt weathering (Dessert et al. 2003). For a region in the Swiss Alps fluvial silica concentration is correlated with both temperature and elevation (Drever and Zobrist 1992). In case of Japan spatial correlations of temperature with other factors, like climate (precipitation and runoff) and elevation (partly represented by slope) exist. The multiple linear correlation coefficient between temperature, slope and runoff of $r=0.56 \quad(p<0.0001)$ shows that temperature may be partly substituted by annual runoff and slope (Fig. 9). This interpretation is substantiated by the high correlation between observed and predicted specific DSi-fluxes according to Eq. 1 (Fig. 6).

The temperature approach is also hindered by the circumstance that surface air temperature was applied in this study (as well as in previous studies) and that surface temperature may not be representative of temperatures below ground where chemical weathering takes place, e.g., by plant cover influences (compare for further references Anderson et al. 2007). However, temperature effect may have been detected if a larger temperature range would have existed (cf. Dessert et al. 2003). 


\section{Anthropogenic effects}

The contribution of anthropogenic DSi, specifically in the 1940s and 1950s, when most water samples were taken, is expected to have been very low (Van Dokkum et al. 2004; Garnier et al. 2006). Today, some proportion of DSi can be attributed to detergent use. Since the 1960s an increasing usage of silica containing detergent is noticed in developed countries (Garnier et al. 2006), but anthropogenic contribution to total DSi-fluxes is estimated to be less than $2 \%$ (Van Dokkum et al. 2004).

\section{Lake effects}

The largest lake in Japan is Lake Biwa, with an area of $670 \mathrm{~km}^{2}$, and a catchment of $3,267 \mathrm{~km}^{2}$ (according to the digital elevation model). About $70 \%$ of the DSi input is retained in the lake (Harashima et al. 2006), reducing the DSi-flux to the Seto Inland Sea by $0.038 \times 10^{6} \mathrm{t} \mathrm{SiO}_{2} \mathrm{a}^{-1}$ and total Japanese output by $\sim 0.46 \%$ (if compared to the forced model approach fluxes). All lakes and water bodies of Japan amount to $2,375 \mathrm{~km}^{2}$, of which Lake Biwa represents $28.2 \%$. Thus, the retention of all lakes (using the lake Biwa estimate) should be $\sim 1.5 \%$ for all of Japan.

At the time when Kobayashi conducted his surveys only a few large reservoirs existed in the monitored catchments. The influence of instream diatoms DSiuptake is probably low because Japanese rivers are short and channel slope is steep. This hypothesis is supported by measurements yielding only low ASi proportions of total Si in Japanese waters (Isaji 2003; Harashima et al. 2006).

Implications for the global carbon cycle

Results indicate that Japan, and probably the entire "Ring of Fire", are hyperactive with respect to DSi-fluxes. A global estimate of DSi-fluxes to coastal zones supports this interpretation (Dürr et al. 2008). Nevertheless the overall DSi concentration in surface waters of the Pacific is low (Levitus et al. 1993). Both observations support the hypothesis that regions of high tectonic activity may be a factor controlling marine carbon burial rates due to high terrestrial DSi-inputs that stimulate growth of diatoms. Diatom frustules and accompanied particulate organics sink faster to the ocean floor providing less time for remineralisation than organic matter bound to other phytoplankton species, thus leading to higher accumulation and possibly carbon burial rates (Buesseler et al. 2007; Harashima 2007). Thus, the study of regional distribution of DSi-fluxes does not only improve our understanding of the carbon cycle but may also lead to spin-offs regarding the role of tectonically active times in the geological past and global biogeochemical cycles.

Volcanic areas are important for the carbon cycle also in another aspect: their $\mathrm{CO}_{2}$ consumption during chemical weathering of silicates (cf. Dessert et al. 2001, 2003; Dupre et al. 2003). Herein it is shown that slope is an important controlling factor for silicate weathering rates. However, steep regions in subtropical or tropical humid climates with high proportions of volcanics are not very well represented in data sets for model calibration in recent global estimates of $\mathrm{CO}_{2}$-consumption by weathering (cf. Ludwig et al. 1998, 1999; Gaillardet et al. 1999). In addition, the factor slope (relief) is not included in the cited weathering models. Large rivers are often used for model evaluation. However, lithological distribution of 60 large river basins, e.g., applied by Gaillardet et al. (1999), does not differ much from the regions not covered by these large basins (Table 1). Because slope was not subject of previous global weathering studies it can only be speculated if considering its global pattern will influence the estimates of global $\mathrm{CO}_{2}$-consumption by chemical weathering (currently at $\left.0.25-0.26 \mathrm{Gt} \mathrm{C} \mathrm{a}^{-1}\right)$. For further discussion of this issue see Hartmann (2008).

\section{Conclusion}

This study presents a new approach for predicting DSi-fluxes on a regional scale that may also be applied on a global scale after modifying the approach. Only three factors are considered in this prediction model because of certain specific conditions of the Japanese Archipelago (i.e., land cover, temperature, soil characteristics, etc.).

Japan constitutes a hyperactive region (10\% of its area can even be characterized as hot spot region) with respect to DSi-fluxes, exceeding the global average of DSi-fluxes by a factor of 6.6 (cf. Dürr et al. 2008). Besides runoff, slope constitutes another important factor controlling chemical weathering of silicates and can exceed runoff as first-order control in some cases. Future models may be improved by incorporating mechanistic components such as the lake effect for DSi retention. In addition, the firstorder controlling factors applied here (lithology, runoff and slope) can be used in a mechanistic model approach. More research is needed to test and incorporate further factors like temperature, atmospheric deposition, land cover or anthropogenic influences. Applicable functional relationships for prediction equations need to be identified and influences of correlations among predictors have to be addressed. Moreover, to enhance the presented approach, reliable river hydrochemical data are needed for model 
calibration and specifically the influence of seasonality should be addressed. Seasonality influence is important in case larger catchments or basins should be recognized in a lumped model approach, because specifically larger river systems are often characterized by strong DSi concentration seasonality, partly controlled by nutrient loads and thus by anthropogenic influence (cf. Hartmann et al. 2007a).

Acknowledgments Authors are grateful to the overall cooperation of Takashi Kimoto in digitizing the hand-written tables of Kobayashi's river data. This work was supported by the Global Environment Research Fund from Ministry of Environment, Japan; Grant No. D3(FY2002-2004) and D061(FY2006-2008). Saho Hartmann-Suzuki and Osamu Suzuki helped verifying sampling locations. Travel funds needed for this study were supported by Family Hartmann. Hans Dürr has been funded by the EU programme Si WEBS (contract number HPRN-CT-2002-000218) and by Utrecht University (high potential project G-NUX). This study was conducted preparing the global river project (HA 4472/6-1) funded by the German Research Foundation (DFG).

\section{Appendix A}

Distribution of precipitation and atmospheric hydrochemical deposition patterns were calculated from the following references. Based on the regional patterns of both factors silica deposition was interpolated using the product of silica concentration in atmospheric deposition and annual average precipitation.

Anazawa K, Ohmori H (2005) The hydrochemistry of surface waters in andesitic volcanic area, Norikura volcano, central Japan. Chemosphere 59:605-615

Anazawa K, Sakamoto H, Tomiyasu T (2007) Influence of ignimbrite on the chemistry of river water in Shirasu plateau, Japan. Hydrogeol J 15:409-417

Asano Y, Ohte N, Uchida T (2004) Sources of weathering-derived solutes in two granitic catchments with contrasting forest growth. Hydrol Process 18:651-666

Farah A, Rahman A, Hiura H, Shino K (2006) Trends of bulk precipitation and streamwater chemistry in a small mountainous watershed on the Shikoku Island of Japan. Water Air Soil Pollut 175:257-273

Fujita S, Takahashi A, Weng JH, Huang LF, Kim HK, Li CK, Huang FTC, Jeng FT (2000) Precipitation chemistry in East Asia. Atmos Environ 34:525-537

Fujita SI, Takahashi A, Sakurai T (2003) The wet deposition of acid and some major ions over the Japanese Archipelago. Tellus Ser B Chem Phys Meteorol 55:23-34

Fukuzaki N, Oshio T, Noguchi I, Matsumoto M, Morisaki S, Oohara M, Tamaki M, Hiraki T (1999) Spatial differences of chemical features of atmospheric deposition between rainy season and winter in the areas facing to the Japan Sea, Japan. Chemosphere 38:411-423

Hara H (1993) Acid deposition chemistry in Japan. Bull Inst Public Health 43:426-437

Hara H (1997) Chemistry of precipitation water in Japan. Nippon Kagakukaishi 11:733-748

Kunimatsu T, Hamabata E, Sudo M, Hida Y (2001) Comparison of nutrient budgets between three forested mountain watersheds on granite bedrock. Water Sci Technol 44:129-140

Lee BK, Hong SH, Lee DS (2000) Chemical composition of precipitation and wet deposition of major ions on the Korean peninsula. Atmos Environ 34:563-575

Nakagawa Y, Iwatsubo G (2000) Water chemistry in a number of mountainous streams of East Asia. J Hydrol 240:118-130

Okuda T, Iwase T, Ueda H, Suda Y, Tanaka S, Dokiya Y, Fushimi K, Hosoe M (2005) Long-term trend of chemical constituents in precipitation in Tokyo metropolitan area, Japan, from 1990 to 2002: Sci Total Environ 339:127-141

Rasyidin A, Wakatsuki T (1994) Characterization of precipitation and river water chemistry for measuring rates of weathering and soil formation in Iu river watershed, southwestern Japan. Soil Sci Plant Nutr 40:319-332

Satake H, Yamane T (1992) Deposition of non-sea salt sulfate observed at Toyama facing the sea of Japan for the period of 1981-1991. Geochem J 26:299-305

Seto S, Hara H (2006) Precipitation chemistry in western Japan: its relationship to meteorological parameters. Atmos Environ 40:1538-1549

Seto S, Hara H, Sato M, Noguchi I, Tonooka Y (2004) Annual and seasonal trends of wet deposition in Japan. Atmos Environ 38:3543-3556

Seto S, Nakamura A, Noguchi I, Ohizumi T, Fukuzaki N, Toyama S, Maeda M, Hayashi K, Hara H (2002) Annual and seasonal trends in chemical composition of precipitation in Japan during 1989-1998. Atmos Environ 36:35053517

Zhang J, Zhang GS, Liu SM (2005) Dissolved silicate in coastal marine rainwaters: comparison between the Yellow Sea and the East China Sea on the impact and potential link with primary production. J Geophys Res Atmos 110

\section{Appendix B}

Figure 11 
Fig. 11 Relationships between specific DSi-fluxes, runoff and slope for catchments dominated ( $>60 \%$ areal proportion) by one lithological class
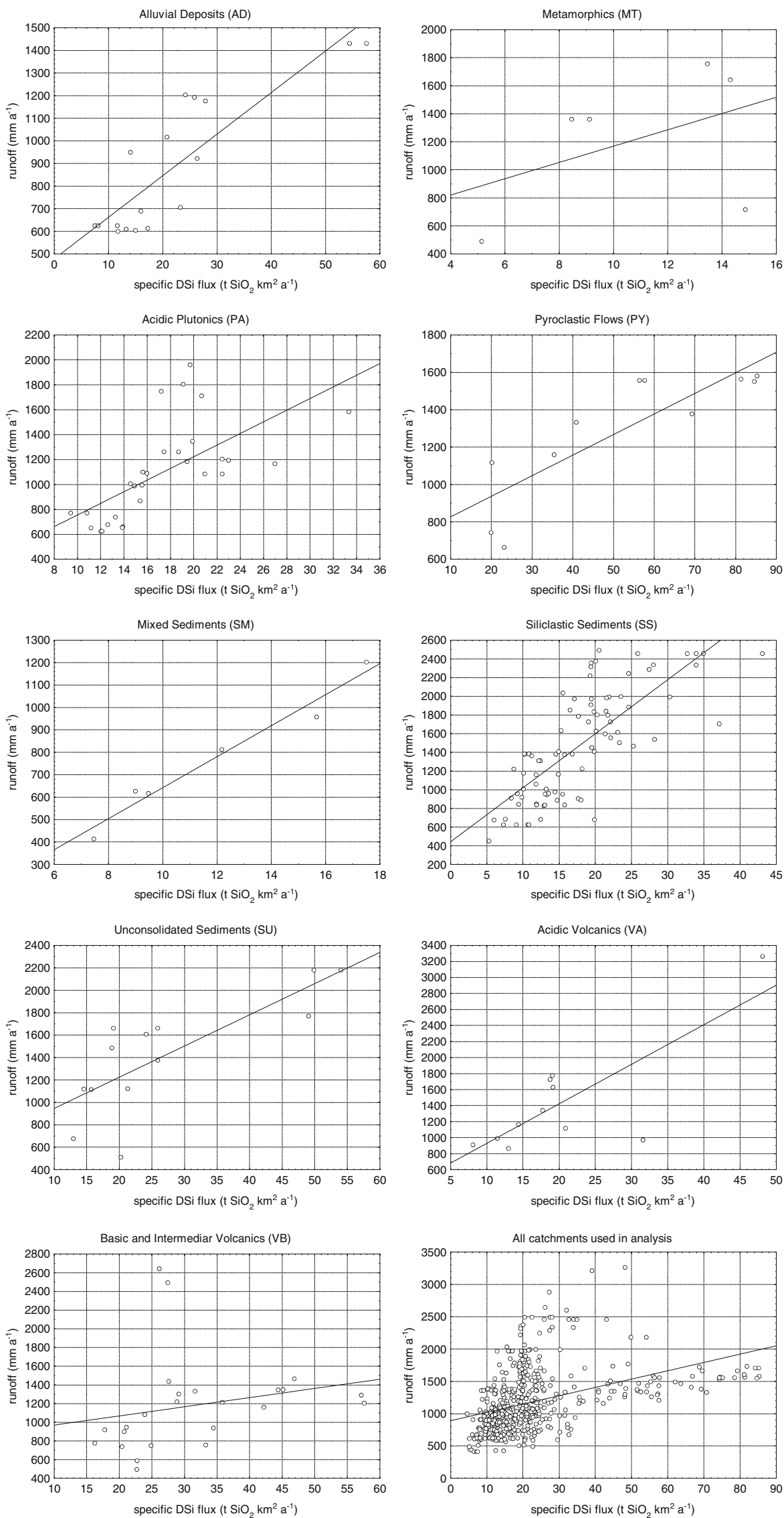
Fig. 11 continued

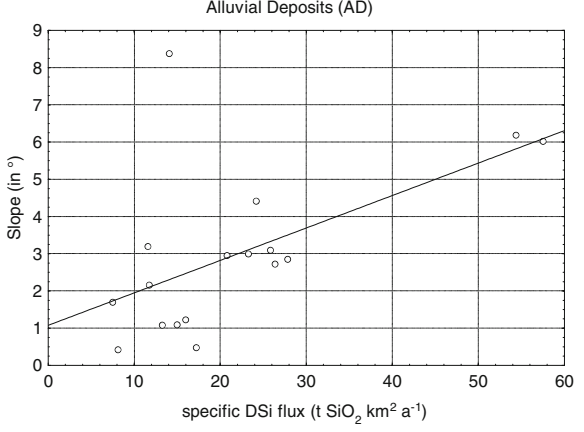

Acidic Plutonics (PA)

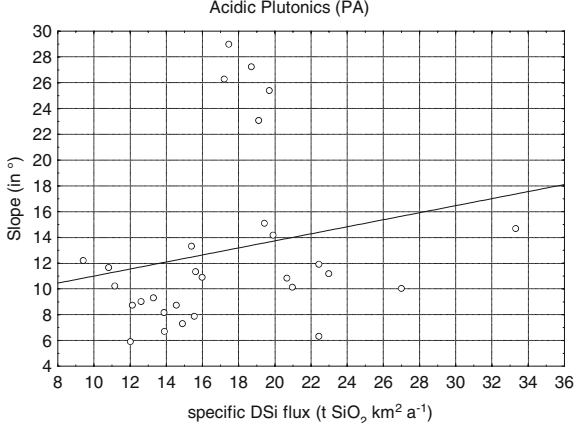

Mixed Sedimentary Rocks (SM)
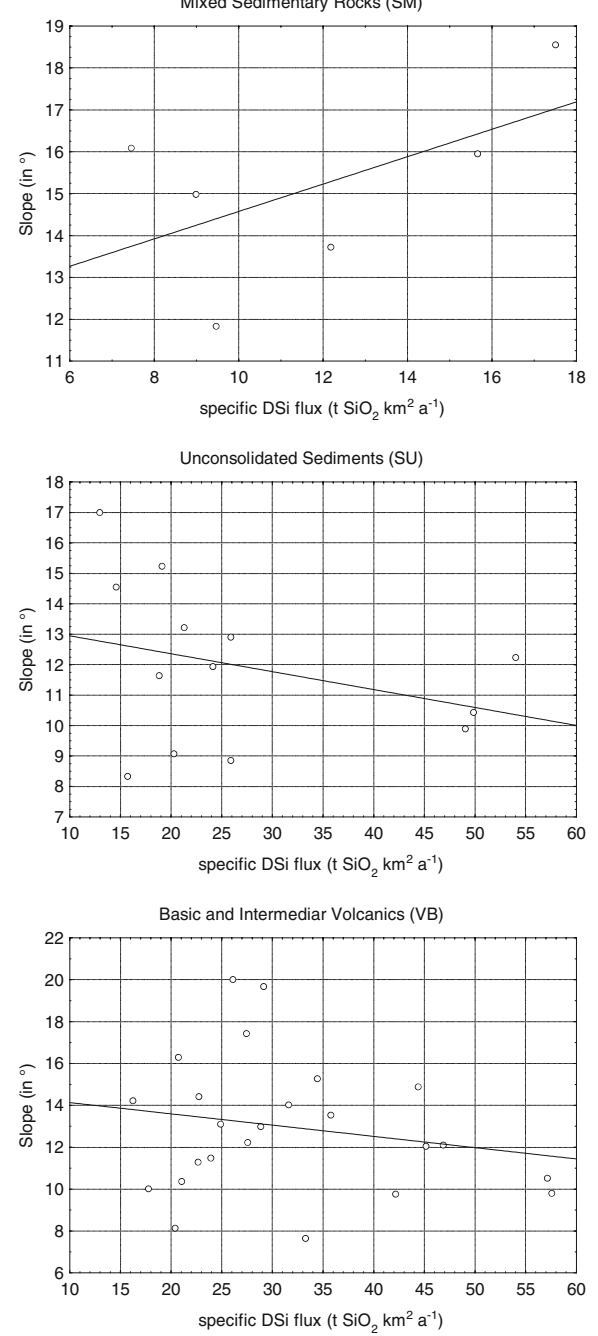
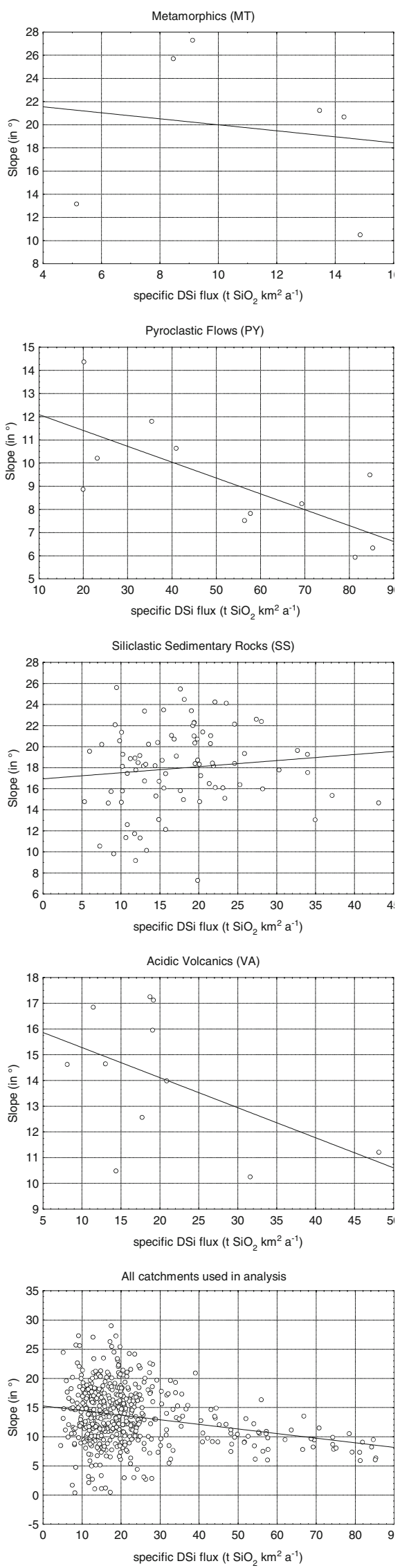


\section{References}

Alexandre A, Meunier JD, Colin F, Koud JM (1997) Plant impact on the biogeochemical cycle of silicon and related weathering processes. Geochim Cosmochim Acta 61(3):677-682

Amiotte-Suchet P, Probst JL, Ludwig W (2003) Worldwide distribution of continental rock lithology: implications for the atmospheric/soil $\mathrm{CO}_{2}$ uptake by continental weathering and alkalinity river transport to the oceans. Glob Biogeochem Cycle 17(2): 1038

Anazawa K, Ohmori H (2005) The hydrochemistry of surface waters in andesitic volcanic area, Norikura volcano, central Japan. Chemosphere 59(5):605-615

Anderson SP, von Blanckenburg F, White AF (2007) Physical and chemical controls on the critical zone. Elements 3(5):315-319

Asano Y, Uchida T (2005) Quantifying the role of forest soil and bedrock in the acid neutralization of surface water in steep hillslopes. Environ Pollut 133(3):467-480

Asano Y, Uchida T, Ohte N (2003) Hydrologic and geochemical influences on the dissolved silica concentration in natural water in a steep headwater catchment. Geochim Cosmochim Acta 67(11):1973-1989

Asano Y, Ohte N, Uchida T (2004) Sources of weathering-derived solutes in two granitic catchments with contrasting forest growth. Hydrol Process 18(4):651-666

Batjes NH (2006) ISRIC-WISE derived soil properties on a 5 by 5 arcminutes global grid Ver. 1.1-Soter soil data base. ISRIC World Soil Information

Berner RA, Kothavala Z (2001) GEOCARB III: a revised model of atmospheric $\mathrm{CO}_{2}$ over phanerozoic time. Am J Sci 301(2):182204

Beusen AHW, Dekkers ALM, Bouwman AF, Ludwig W, Harrison J (2005) Estimation of global river transport of sediments and associated particulate $\mathrm{C}, \mathrm{N}$, and $\mathrm{P}$. Glob Biogeochem Cycle 19(4):GB4S05

Bluth GJS, Kump LR (1994) Lithologic and climatologic controls of river chemistry. Geochim Cosmochim Acta 58(10):2341-2359

Bouwman AF, Van Drecht G, Knoop JM, Beusen AHW, Meinardi CR (2005) Exploring changes in river nitrogen export to the world's oceans. Glob Biogeochem Cycle 19(1):GB1002

Buesseler KO, Lamborg CH, Boyd PW, Lam PJ, Trull TW, Bidigare RR, Bishop JKB, Casciotti KL, Dehairs F, Elskens M, Honda M, Karl DM, Siegel DA, Silver MW, Steinberg DK, Valdes J, Van Mooy B, Wilson S (2007) Revisiting carbon flux through the ocean's twilight zone. Science 316(5824):567-570

Chen CTA, Andreev A, Kim KR, Yamamoto M (2004) Roles of continental shelves and marginal seas in the biogeochemical cycles of the North Pacific Ocean. J Oceanogr 60(1):17-44

Conley DJ (2002) Terrestrial ecosystems and the global biogeochemical silica cycle. Glob Biogeochem Cycle 16(4):1121

Dessert C, Dupre B, Francois LM, Schott J, Gaillardet J, Chakrapani G, Bajpai S (2001) Erosion of Deccan Traps determined by river geochemistry: impact on the global climate and the Sr-87/Sr- 86 ratio of seawater. Earth Planet Sci Lett 188(3-4):459-474

Dessert C, Dupre B, Gaillardet J, Francois LM, Allegre CJ (2003) Basalt weathering laws and the impact of basalt weathering on the global carbon cycle. Chem Geol 202:257-273

Drever JI, Zobrist J (1992) Chemical-weathering of silicate rocks as a function of elevation in the southern Swiss Alps. Geochim Cosmochim Acta 56(8):3209-3216

Dupre B, Dessert C, Oliva P, Godderis Y, Viers J, Francois L, Millot R, Gaillardet J (2003) Rivers, chemical weathering and Earth's climate. C R Geosci 335(16):1141-1160

Dürr HH, Meybeck M, Dürr SH (2005) Lithologic composition of the Earth's continental surfaces derived from a new digital map emphasizing riverine material transfer. Glob Biogeochem Cycle 19(4):GB4S10

Dürr HH, Meybeck M, Hartmann J, Laruelle GG, Roubeix V (2008) Global spatial distribution of natural riverine silica inputs to the coastal zone. Biogeosciences (in review)

Fekete BM, Vörösmarty CJ, Grabs W (2002) High-resolution fields of global runoff combining observed river discharge and simulated water balances. Glob Biogeochem Cycle 16(3):1042

Frey KE, Smith LC (2007) How well do we know northern land cover? Comparison of four global vegetation and wetland products with a new ground-truth database for West Siberia. Glob Biogeochem Cycle 21(1):GB1016

Fulweiler RW, Nixon SW (2005) Terrestrial vegetation and the seasonal cycle of dissolved silica in a southern New England coastal river. Biogeochemistry 74(1):115-130

Gaillardet J, Dupre B, Louvat P, Allegre CJ (1999) Global silicate weathering and $\mathrm{CO}_{2}$ consumption rates deduced from the chemistry of large rivers. Chem Geol 159(1-4):3-30

Garnier J, Billen G, Hannon E, Fonbonne S, Videnina Y, Soulie M (2002) Modelling the transfer and retention of nutrients in the drainage network of the Danube River. Estuar Coast Shelf Sci 54(3):285-308

Garnier J, Sferratore A, Meybeck M, Billen G, Dürr H (2006) Modelling silica transfer processes in river catchments. In: Ittekkot V, Unger D, Humborg C, Tac An N (eds) Role of silica in land-sea interactions. Island Press, Washington, DC, pp 139-162

Geological Survey of Japan (2003) Geological map of Japan 1:1,000,000, 3rd edn, 2nd CD-ROM Version. Geological Survey of Japan

Gislason SR, Arnorsson S, Armannsson H (1996) Chemical weathering of basalt in southwest Iceland: effects of runoff, age of rocks and vegetative/glacial cover. Am J Sci 296(8):837-907

Harashima A (2007) Evaluating the effects of change in input ratio of $\mathrm{N}: \mathrm{P}: \mathrm{Si}$ to coastal marine ecosystem. J Environ Sci Sust Soc $1: 33-38$

Harashima A, Kimoto T, Wakabayashi T, Toshiyasu T (2006) Verification of the silica deficiency hypothesis based on biogeochemical trends in the aquatic continuum of Lake BiwaYodo River-Seto Inland Sea, Japan. Ambio 35(1):36-42

Hartmann J (2005) Difference information criterion for the analysis of a seismotectonic influence on a radon time-series at the KSM site, Japan. Geophys J Int 160(3):891-900

Hartmann J (2006) Long-term seismotectonic influence on the hydrochemical composition of a spring located at KoryakskyVolcano, Kamchatka: deduced from aggregated earthquake information. Int J Earth Sci 95(4):649-664

Hartmann J (2008) Analysis of $\mathrm{CO}_{2}$-consumption and dissolved silica fluxes caused by chemical weathering: steps towards modelling dissolved matter fluxes on regional and global scales. Habilitation thesis, Institute of Applied Geosciences, Darmstadt University of Technology, Darmstadt

Hartmann J, Berner Z, Stuben D, Henze N (2005) A statistical procedure for the analysis of seismotectonically induced hydrochemical signals: a case study from the Eastern Carpathians, Romania. Tectonophysics 405(1-4):77-98

Hartmann J, Levy JK, Okada N (2006) Managing surface water contamination in Nagoya, Japan: an integrated water basin management decision framework. Water Res Manag 20(3):411430

Hartmann J, Jansen N, Kempe S, Dürr HH (2007a) Geochemistry of the river Rhine and the upper Danube: Recent trends and lithological influence on baselines. J Environ Sci Sust Soc 1:39-46

Hartmann J, Kunimatsu T, Levy JK (2007b) The impact of eurasian dust storms and anthropogenic emissions on atmospheric nutrient deposition rates in forested Japanese catchments and 
adjacent regional seas. Glob Planet Change. doi:10.1016/j. gloplacha.2007.08.001

Hartmann J, Dürr HH, Kempe S, Jansen N (2009) Analysis of the spatial distribution of global $\mathrm{CO}_{2}$-consumption by chemical weathering. Glob Planet Change (in review)

Humborg C, Blomqvist S, Avsan E, Bergensund Y, Smedberg E, Brink J, Morth CM (2002) Hydrological alterations with river damming in northern Sweden: implications for weathering and river biogeochemistry. Glob Biogeochem Cycle 16(3):1039

Humborg C, Pastuszak M, Aigars J, Siegmund H, Morth CM, Ittekkot V (2006) Decreased silica land-sea fluxes through damming in the Baltic Sea catchment-significance of particle trapping and hydrological alterations. Biogeochemistry 77(2):265-281

International Water Management Institute (2000) World water and climate atlas. http://www.iwmi.cgiar.org/WAtlas/, 2004 (access date)

Isaji C (2003) Silica fractionation: a method and differences between two Japanese reservoirs. Hydrobiologia 504(1-3):31-38

Kawai T, Kano A, Matsuoka J, Ihara T (2006) Seasonal variation in water chemistry and depositional processes in a tufa-bearing stream in SW-Japan, based on 5 years of monthly observations. Chem Geol 232(1-2):33-53

Kempe S (1979) Carbon in the rock cycle. In: Bolin B, Degens ET, Kempe S, Ketner P (eds) The global carbon cycle-scope 13. Scientific Committee on Problems on the Environment (SCOPE), Old Woking, pp 343-375

Kempe S, Degens ET (1985) An early soda ocean. Chem Geol 53(12):95-108

Kobayashi J (1960) A chemical study of the average quality and characteristics of river waters of Japan. Berichte Ohara-Inst Landwirtschaftl Biol 11(3):313-357

Krishnan R, Sugi M (2001) Baiu rainfall variability and associated monsoon teleconnections. J Meteorol Soc Japan 79(3):851-860

Kristiansen S, Hoell EE (2002) The importance of silicon for marine production. Hydrobiologia 484(1-3):21-31

Kump LR, Brantley SL, Arthur MA (2000) Chemical, weathering, atmospheric $\mathrm{CO}_{2}$, and climate. Ann Rev Earth Planet Sc 28:611667

Lenton TM, Britton C (2006) Enhanced carbonate and silicate weathering accelerates recovery from fossil fuel $\mathrm{CO}_{2}$ perturbations. Glob Biogeochem Cycle 20(3):GB3009

Levitus S, Conkright ME, Reid JL, Najjar RG, Mantyla A (1993) Distribution of nitrate, phosphate and silicate in the world oceans. Prog Oceanogr 31(3):245-273

Lucas Y (2001) The role of plants in controlling rates and products of weathering: importance of biological pumping. Ann Rev Earth Planet Sci 29:135-163

Ludwig W, Probst JL, Kempe S (1996) Predicting the oceanic input of organic carbon by continental erosion. Glob Biogeochem Cycle 10(1):23-41

Ludwig W, Amiotte-Suchet P, Munhoven G, Probst JL (1998) Atmospheric $\mathrm{CO}_{2}$ consumption by continental erosion: presentday controls and implications for the last glacial maximum. Glob Planet Change 17:107-120

Ludwig W, Amiotte-Suchet P, Probst JL (1999) Enhanced chemical weathering of rocks during the last glacial maximum: a sink for atmospheric $\mathrm{CO}_{2}$ ? Chem Geol 159(1-4):147-161

Lyons WB, Carey AE, Hicks DM, Nezat CA (2005) Chemical weathering in high-sediment-yielding watersheds, New Zealand. J Geophys Res Earth Surf 110(F1):F01008

Ma JF, Takahashi E (1989) Release of silicon from rice straw under flooded conditions. Soil Sci Plant Nutr 35(4):663-667

Ma JF, Nishimura K, Takahashi E (1989) Effect of silicon on the growth of rice plant at different growth-stages. Soil Sci Plant Nutr 35(3):347-356
Meunier JD, Colin F, Alarcon C (1999) Biogenic silica storage in soils. Geology 27(9):835-838

Meybeck M (2005) Global occurrence of major elements in rivers. In: Drever JI (ed) Surface and groundwater, weathering and soils. Elsevier/Pergamon, Oxford, pp 207-223

Meybeck M, Ragu A (1995) GEMS/water contribution to the global register of river inputs (GLORI). Provisional Final Report, UNEP/WHO/UNESCO, Geneva

Meybeck M, Dürr HH, Vörösmarty CJ (2006) Global coastal segmentation and its river catchment contributors: a new look at landocean linkage. Global Biogeochem Cycles 20(1):GB1S90

Meybeck M, Dürr HH, Roussennac S, Ludwig W (2007) Regional seas and their interception of riverine fluxes to oceans. Mar Chem 106:301-325

Millot R, Gaillardet J, Dupre B, Allegre CJ (2002) The global control of silicate weathering rates and the coupling with physical erosion: new insights from rivers of the Canadian Shield. Earth Planet Sci Lett 196(1-2):83-98

Moulton KL, West J, Berner RA (2000) Solute flux and mineral mass balance approaches to the quantification of plant effects on silicate weathering. Am J Sci 300(7):539-570

Okuda I, Okazaki M, Hashitani T (1995) Spatial and temporal variations in the chemical-weathering of basaltic pyroclastic materials. Soil Sci Soc Am J 59(3):887-894

Rad S, Louvat P, Gorge C, Gaillardet K, Allegre CJ (2006) River dissolved and solid loads in the Lesser Antilles: new insight into basalt weathering processes. J Geochem Exp 88(1-3):308-312

Root TL, MacMynowski DP, Mastrandrea MD, Schneider SH (2005) Human-modified temperatures induce species changes: joint attribution. Proc Natl Acad Sci USA 102(21):7465-7469

Schmarnow U, Berth W, Keller W (1982) Wetterkunde. Transpress, Berlin

Seitzinger SP, Harrison JA, Dumont E, Beusen AHW, Bouwman AF (2005) Sources and delivery of carbon, nitrogen, and phosphorus to the coastal zone: an overview of global Nutrient Export from Watersheds (NEWS) models and their application. Glob Biogeochem Cycle 19(4):GB4S01

Sferratore A, Billen G, Garnier J, Thery S (2005) Modeling nutrient (N,P,Si) budget in the Seine watershed: application of the Riverstrahler model using data from local to global scale resolution. Glob Biogeochem Cycle 19(4):GB4S07

Sidle RC, Tsuboyama Y, Noguchi S, Hosoda I, Fujieda M, Shimizu T (2000) Stormflow generation in steep forested headwaters: a linked hydrogeomorphic paradigm. Hydrol Process 14(3):369385

Syvitski JPM, Milliman JD (2007) Geology, geography, and humans battle for dominance over the delivery of fluvial sediment to the coastal ocean. J Geol 115(1):1-19

Takai F, Matsumoto T, Toriyama R (1963) Geology of Japan. University of California, Berkley

Tateishi R, Zhu L, Sato HP (2003) The land cover map for Central Asia for the year 2000. European Commision Joint Research Center

Tréguer P, Nelson DM, Van Bennekom AJ, De Master DJ, Leynaert A, Queguiner B (1995) The silica balance in the world ocean-a reestimate. Science 268(5209):375-379

Turner RE, Rabalais NN, Justic D, Dortch Q (2003) Global patterns of dissolved $\mathrm{N}, \mathrm{P}$ and $\mathrm{Si}$ in large rivers. Biogeochemistry 64(3):297-317

Van Dokkum HP, Hulskotte JHJ, Kramer KJM, Wilmot J (2004) Emission, fate and effects of soluble silicates (waterglass) in the aquatic environment. Environ Sci Technol 38(2):515-521

Verstraeten G (2006) Regional scale modelling of hillslope sediment delivery with SRTM elevation data. Geomorphology 81(12): $128-140$ 
Verstraeten G, Poesen J (2002) Regional scale variability in sediment and nutrient delivery from small agricultural watersheds. J Environ Quality 31(3):870-879

West AJ, Galy A, Bickle M (2005) Tectonic and climatic controls on silicate weathering. Earth Planet Sci Lett 235(1-2):211-228
White AF, Blum AE, Bullen TD, Vivit DV, Schulz M, Fitzpatrick J (1999) The effect of temperature on experimental and natural chemical weathering rates of granitoid rocks. Geochim Cosmochim Acta 63(19-20):3277-3291 